IAB-DISCUSSION PAPER Articles on labour market issues

3|2019 Hartz IV and the Decline of German Unemployment: A Macroeconomic Evaluation

Brigitte Hochmuth, Britta Kohlbrecher, Christian Merkl, Hermann Gartner 


\title{
Hartz IV and the Decline of German Unemployment: A Macroeconomic Evaluation
}

\author{
Brigitte Hochmuth (Friedrich-Alexander Universität Erlangen-Nürnberg) \\ Britta Kohlbrecher (Friedrich-Alexander Universität Erlangen-Nürnberg) \\ Christian Merkl (Friedrich-Alexander Universität Erlangen-Nürnberg and IAB) \\ Hermann Gartner (IAB and Friedrich-Alexander Universität Erlangen-Nürnberg)
}

Mit der Reihe „IAB-Discussion Paper“ will das Forschungsinstitut der Bundesagentur für Arbeit den Dialog mit der externen Wissenschaft intensivieren. Durch die rasche Verbreitung von Forschungsergebnissen über das Internet soll noch vor Drucklegung Kritik angeregt und Qualität gesichert werden.

The "IAB Discussion Paper" is published by the research institute of the German Federal Employment Agency in order to intensify the dialogue with the scientific community. The prompt publication of the latest research results via the internet intends to stimulate criticism and to ensure research quality at an early stage before printing. 


\section{Contents}

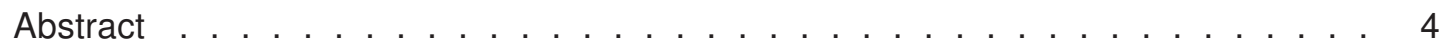

Zusammenfassung . . . . . . . . . . . . . . . . . . . . . 4

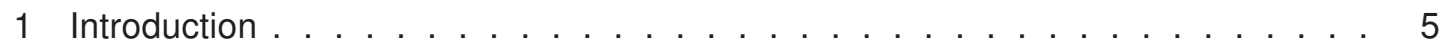

2 The Unemployment Benefit Reform . . . . . . . . . . . . . . . . . 8

3 The Model . . . . . . . . . . . . . . . . . . . . . . . . . . . . . . . 10

3.1 Firm's Problem . . . . . . . . . . . . . . . . . . . . . . . . . . . . . . 11

3.2 Worker's Problem . . . . . . . . . . . . . . . . . . . . . 13

3.3 Contacts . . . . . . . . . . . . . . . . . . . . . . . . 14

3.4 Unemployment Dynamics . . . . . . . . . . . . . . . . . . . . . . . . . . 14

3.5 Wages . . . . . . . . . . . . . . . . . . . . . . . 15

3.6 Labour Market Equilibrium . . . . . . . . . . . . . . . . . . . . . . . 15

4 Empirical Strategy . . . . . . . . . . . . . . . . . . . . . . . . . . 16

4.1 Measuring Selection . . . . . . . . . . . . . . . . . . . 17

4.2 Linking the Model to the Data . . . . . . . . . . . . . . . . 19

4.3 Determining the Partial Effect . . . . . . . . . . . . . . . . . 21

4.4 Determining the Importance of Partial and Equilibrium Effect . . . . . . . 26

5 Calibration . . . . . . . . . . . . . . . . . . . 28

6 The Effects of Hartz IV . . . . . . . . . . . . . . . . . . . . . . . . . 30

6.1 Partial Effects . . . . . . . . . . . . . . . . . . . . . 30

6.2 Equilibrium Effects . . . . . . . . . . . . . . . . . . 33

6.3 Broader Perspective . . . . . . . . . . . . . . . . . . 35

7 Conclusion . . . . . . . . . . . . . . . . . . . . . 37

A Appendix: Details on the Hartz Reforms . . . . . . . . . . . . . . . 38

B Appendix: Data . . . . . . . . . . . . . . . . . . . . 39

B.1 Appendix: Details on the IAB Job Vacancy Survey . . . . . . . . . . . . . 39

B.2 Appendix: Details on the IAB PASS Survey . . . . . . . . . . . . . . . 40

C Appendix: Model Robustness . . . . . . . . . . . . . . . . . . . . . . . . . 40

C.1 Collective Bargaining . . . . . . . . . . . . . . . . . . . . . 40 40

C.2 Matching Efficiency Shock . . . . . . . . . . . . . . . . . . . 41

D Appendix: Robustness of Empirical Strategy . . . . . . . . . . . . . . . . . . 41

D.1 Robustness of Partial Effect Estimations . . . . . . . . . . . . . . . . . . 41

D.2 Correction of Unemployment Series . . . . . . . . . . . . . . . . . . . 44

E Appendix: Further Evidence $\ldots \ldots \ldots$. . . . . . . . . . . . . . . 45 


\section{Abstract}

This paper proposes a new approach to evaluate the macroeconomic effects of the Hartz IV reform in Germany, which reduced the generosity of long-term unemployment benefits. We use a model with different unemployment durations, where the reform initiates both a partial effect and an equilibrium effect. The relative importance of these two effects and the size of the partial effect are estimated based on the IAB Job Vacancy Survey. Our novel methodology provides a solution for the existing disagreement in the macroeconomic literature on the unemployment effects of Hartz IV. We find that Hartz IV was a major driver for the decline of Germany's unemployment and that partial and equilibrium effect where of equal importance. We thereby contribute to the literature on partial and equilibrium effects of unemployment benefit changes. In addition, we are the first to provide direct empirical evidence on labour selection, which can be interpreted as one dimension of recruiting intensity.

\section{Zusammenfassung}

Wir analysieren mit Hilfe eines neuen Ansatzes die gesamtwirtschaftlichen Arbeitsmarkteffekte der Hartz IV Reform. Mit der Reform wurden die Lohnersatzleistungen für viele Langzeitarbeitslose gekürzt. Wir verwenden ein Modell mit unterschiedlichen Arbeitslosigkeitsdauern, in dem die Reform sowohl einen Partial- als auch einen Gleichgewichtseffekt auslöst. Die relative Bedeutung dieser beiden Effekte und die Höhe des Partialeffektes werden mit Hilfe der Stellenerhebung des IABs geschätzt. Unser Ergebnis ist, dass die Hartz IV Reform eine wichtige Ursache für die seit 2005 sinkende Arbeitslosigkeit in Deutschland darstellt, wobei der Partialeffekt und der Gleichgewichtseffekt etwa gleichbedeutend waren. Wir sind die ersten, die zeigen, wie selektiv sich Betriebe bei Neueinstellungen über den Konjunkturverlauf verhalten, was wir als eine Dimension der Rekrutierungsintensität interpretieren.

\section{JEL classification: E24, E00, E60}

Keywords: Unemployment benefits reform, search and matching, Hartz reforms

Acknowledgements: We are grateful for feedback at the following conferences/workshops: CESifo Conference on Macroeconomics and Survey Data (Munich), Ensuring Economics and Employment Stability (Nuremberg), T2M 2018 (Paris), and Verein für Socialpolitik 2017 (Vienna). We have obtained very useful feedback at departmental seminars at Australian National University, Humboldt Universität, IAB, IWH Halle, Université de Strasbourg, University of Adelaide, University of Bamberg, University of Trier and the University of Queensland. We would like to thank Vincent Sterk for an insightful discussion of our paper and are grateful for feedback from Leo Kaas, Andrey Launov, Kurt Mitman, Mathias Trabandt, and Coen Teulings. We are grateful for funding from the Hans-Frisch-Stiftung. 


\section{Introduction}

From the beginning of the 1970s to the mid 2000s Germany's unemployment rate had been on a rising trend, reaching its maximum in 2005. Since then, it has dropped by roughly 50 percent (see Figure 1). At the beginning of this steep decline in 2005, Germany implemented a major reform of its unemployment benefit system. Before the reform, long-term unemployed received benefits proportional to their prior net earnings. These proportional long-term benefits were abolished in 2005 and replaced by a means-tested transfer (dubbed as "Hartz IV") that is independent of prior earnings and employment history. The Hartz IV reform was the last step in a series of structural labour market reforms (Hartz I - Hartz IV, see Appendix A) implemented between 2003 and 2005.

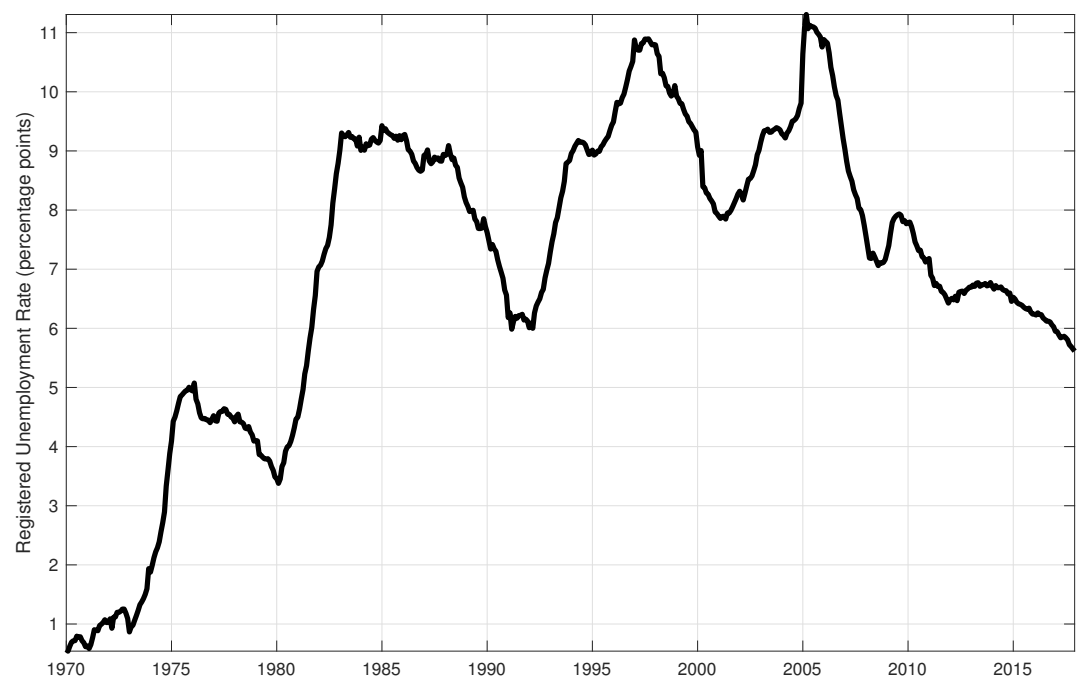

Figure 1: Registered unemployment rate in West Germany, 1970-2017. Note that a long time series is only available for West Germany. Source: Federal Employment Agency.

While the effects of Hartz IV have been studied in the literature before, up to date no clear consensus has emerged on the quantitative importance of the reform for the decline of unemployment. Several papers look at the effects of the Hartz reforms in a reduced-form or descriptive way (Klinger/Rothe, 2012; Hertweck/Sigrist, 2013; Burda/Seele, 2016; CarrilloTudela/Launov/Robin, 2018). Generally, these studies find significant changes of labour market stocks and flows around the time of the Hartz reforms (e.g. a large increase of matching efficiency). However, based on these approaches, it is difficult to discriminate between the different reform steps or to establish a causal link. By contrast, a recent paper by Price (2018) exploits the rich German administrative data to identify causal effects of the Hartz IV reform. He finds statistically significant and economically meaningful employment effects. However, this approach can only identify the partial effect of the reform. If Hartz IV induced further equilibrium effects, e.g. because it affected firms' vacancy posting behaviour, macroeconomic tools are needed.

Krause/Uhlig (2012), Krebs/Scheffel (2013), and Launov/Wälde (2013) all evaluate the reform using simulations of different variants of search (and matching) models of the labour market. ${ }^{1}$ However, their results differ substantially and range from a decline in

\footnotetext{
1 In a recent paper, Bradley/Kuegler 12019, study all Hartz reforms based on a structural estimation of an
} 
unemployment of 0.1 percentage points (Launov/Wälde, 2013) to 2.8 percentage points (Krause/Uhlig, 2012). The key reason for these large discrepancies are different assumptions about the decline of the replacement rate for long-term unemployed caused by the Hartz IV reform. In practice, it has turned out to be very difficult to assign a number to that variable suited for macro models (see Section 2 for details and a discussion). In fact, estimates of the fall of the replacement rate range from just 7 percent (Launov/Wälde, 2013) to nearly 70 percent (upper bound in Krause/Uhlig, 2012). All these studies focus on the role of the job-finding rate in terms of the Hartz IV reform. Recently, Hartung/Jung/Kuhn (2018) analyse the role of the separation rate and find a large role for separations in the context of the Hartz IV reform. ${ }^{2}$

Our paper contributes to the stream of the literature that focuses on the role of job-creation in evaluating the reform. ${ }^{3}$ However, against the background of diverging views on the quantitative effects of the reform, we propose a novel methodology based on a newly created and innovative dataset. Our macroeconomic model of the labour market distinguishes between a partial and an equilibrium effect of the reform. Instead of directly assuming a certain reduction of the replacement rate, we empirically estimate and then target the partial effect of the reform.

In our model, workers have to search and firms have to post vacancies in order to get in contact with one another. Aggregate contacts follow a Cobb-Douglas constant returns contact function with searching workers and vacancies as inputs. New worker-firm contacts draw an idiosyncratic training cost shock. Only workers below a certain training cost threshold will be selected (see e.g. Chugh/Merkl, 2016; Kohlbrecher/Merkl/Nordmeier, 2016; Sedlaĉek, 2014). When benefits for long-term unemployed workers are reduced, the value of unemployment for workers decreases and they are willing to accept lower wages. ${ }^{4}$ This decrease in wages initiates two effects. First, firms post more vacancies and the contact rate of all unemployed workers increases. This represents the equilibrium effect. Second, because of lower wages, firms are willing to hire workers with larger idiosyncratic training costs. Thus, the selection rate increases. This increased hiring probability upon contact represents the partial effect in our model.

Our novel evaluation strategy consists of directly determining the partial effect of the reform by estimating the response of the selection rate in the data. For this purpose, we construct time series for the selection rate using the IAB Job Vacancy Survey, which is a representative survey among up to 14,000 establishments. ${ }^{5}$ To our knowledge, we are the first to i) construct an empirical measure of firms' selection rate (i.e. hiring standards) over time, ii) thereby provide empirical evidence on the importance of the selection margin, and iii) use this to evaluate a labour market reform. The aggregate selection rate increased from 46 percent before the Hartz IV reform (1992-2004) to 53 percent after the Hartz IV reform (from 2005-2015).

\footnotetext{
equilibrium search model.

2 Bauer/King (2018) analyse the effects of the Hartz reform on labour reallocation.

3 Given that we do not take into account separations, our numerical analysis constitutes a lower bound for the aggregate effects of the Hartz IV reform.

4 See Figure E.5 in Appendix E for descriptive empirical evidence based on the IAB Job Vacancy Survey. A substantial fraction of employers answers that Hartz IV has decreased workers' reservation wages.

5 For expositional simplicity, we refer to firms throughout the paper.
} 
Furthermore, we use the business cycle variation of the selection rate and the job-finding rate to determine the relative importance of partial and equilibrium effects. In our model, this pins down the relative size of these two effects in response to unemployment benefit changes. Thus, our paper contributes to the debate on the size of microeconomic and macroeconomic effects of unemployment with respect to benefit changes, which goes beyond the German case. While there are many papers that estimate the microeconomic effects of changing unemployment benefit generosity (see Krueger/Meyer, 2002 for a survey or Card et al., 2015a b for more recent examples) these may only capture part of the overall effect. This argument is stressed in Hagedorn et al. (2013) who estimate the macroeconomic elasticity based on policy discontinuities at state borders in the United States. Our empirical approach is very different and complementary to theirs. To our knowledge, we are the first to use data on the selection rate to pin down the partial and equilibrium effects over the business cycle. ${ }^{6}$

Overall, our calibrated model suggests that the Hartz IV reform caused the German unemployment rate to drop by 2.2 percentage points. Partial and equilibrium effect each account for roughly half of the initial increase of the job-finding rate ${ }^{7}$ Importantly, our partial effect is in a similar order of magnitude as Price's (2018) results, although he uses a completely different methodology. While we estimate the response of the aggregate selection rate from establishment-survey data, Price (2018) obtains causal estimates based on administrative worker-level data. ${ }^{8}$ The decline of the replacement rate needed to generate the targeted partial effect in our model depends on the choice of the bargaining regime (individual Nash or collective bargaining). In both cases, the required decline is within plausible ranges (11 percent and 23 percent). This highlights another important advantage of our approach: By directly targeting the partial effect in our model, our results are robust to different wage formation mechanisms. Our results further demonstrate that the additional equilibrium effect is substantial. Aggregate policy statements that are only based on the partial effect miss an important part of the story. Finally, our model generates a quantitatively similar shift of the Beveridge curve during the three years after the reform as observed in the data from 2005 to 2007. This confirms that our model generates plausible results and that the Hartz IV reform was an important driver of the observed labour market dynamics.

As a further contribution, we are the first to document the time-series behaviour of labour selection, i.e. time-varying hiring standards over the business cycle. As the selection rate moves procyclically and accounts for about one half of the movement of the job-finding rate over the business cycle, it constitutes an important adjustment margin. Our findings close an important research gap as up to date only cross-sectional evidence on the selection margin had been available. Based on the Employment Opportunity Pilot Project (EOPP), Barron/Bishop/Dunkelberg (1985: p. 50) document for the United States that "(...) most employment is the outcome of an employer selecting from a pool of job applicants

\footnotetext{
6 The importance of taking into account equilibrium effects is also stressed by Cahuc/Le Barbanchon I2010, in the context of a different labour market policy.

7 In subsequent periods, a compositional effect comes into play, as workers experience on average shorter unemployment duration associated with higher job-finding rates.

8 Given the similar order of magnitude, we could also calibrate the partial effect based on Price 12018। in our macroeconomic model. The advantage of our approach is that the empirical measures we use directly correspond to our model.
} 
(...)." More recently, Faberman et al. (2017) show based on a supplement to the Survey of Consumer Expectations that only a fraction of worker-firm contacts translate to job offers.

Our empirical results on the business cycle movements of the selection rate are closely related to Davis/Faberman/Haltiwanger (2013) and Gavazza/Mongey/Violante (2018), who argue that the collapse of recruiting intensity played an important role during the Great Recession in the United States. ${ }^{9}$ Our measure of labour selection is one dimension of recruiting intensity. We show that employers hire a larger fraction of applicants in a boom and thereby provide direct evidence that this dimension of recruiting intensity matters over the business cycle.

The rest of the paper proceeds as follows. Section 2 briefly outlines the institutional background on Hartz IV and the consequences for the replacement rate of different population groups. Section 3 derives a suitable search and matching model with labour selection, which allows us to look at the data in a structural way. Section 4 explains our identification strategy for the partial and equilibrium effects and provides empirical results. Section 5 explains the calibration of the contact function and the selection mechanism. Section 6 shows the aggregate partial and equilibrium effects of Hartz IV, performs several numerical exercises and puts the results in perspective to the existing literature. Section 7 concludes.

\section{The Unemployment Benefit Reform}

Prior to the Hartz IV reform, the German unemployment system consisted of three layers. Upon beginning of a new unemployment spell, workers received short-term unemployment benefits ("Arbeitslosengeld"), which amounted to 60-67 percent of the previous net earnings ${ }^{10}$ and was usually paid for 12 months. ${ }^{11}$ After the expiration of short-term benefits, the unemployed received long-term unemployment benefits ("Arbeitslosenhilfe"), which replaced 53-57 percent of the prior net earnings and could be awarded until retirement. If these transfers were not sufficiently high or if unemployed workers did not have a sufficiently long employment history, they obtained means tested social assistance ("Sozialhilfe"). As part of the reform, the proportional long-term unemployment benefits and social assistance were merged to "Arbeitslosengeld II" (ALG II), which is purely means tested based on household income and wealth. The standard rate in 2005 for a single household was 345 Euro. ${ }^{12}$ Thus, the system was merged into two pillars, switching to a means-tested system for the long-term unemployed. In addition, as a second component of Hartz IV, the maximum duration of short-term unemployment benefits for older workers, in particular those above 57, was reduced significantly in 2006. See Figure 2 for an illustration.

As a rule of thumb, the cut of benefits for long-term unemployed was larger for high income and high wealth households. The former faced a large drop because the new system

\footnotetext{
9 While our paper focuses on the time series dimension of the data, Baydur 12017। shows that a selection model can also replicate important cross-sectional dimensions of the data (e.g. the cross-sectional behaviour of vacancy yields, as outlined by Davis/Faberman/Haltiwanger (20131).

10 The higher rate was awarded to recipients with children.

11 The maximum duration of unemployment benefit receipt gradually increased by age for workers older than 45 years.

12 Plus a limited reimbursement for rent.
} 

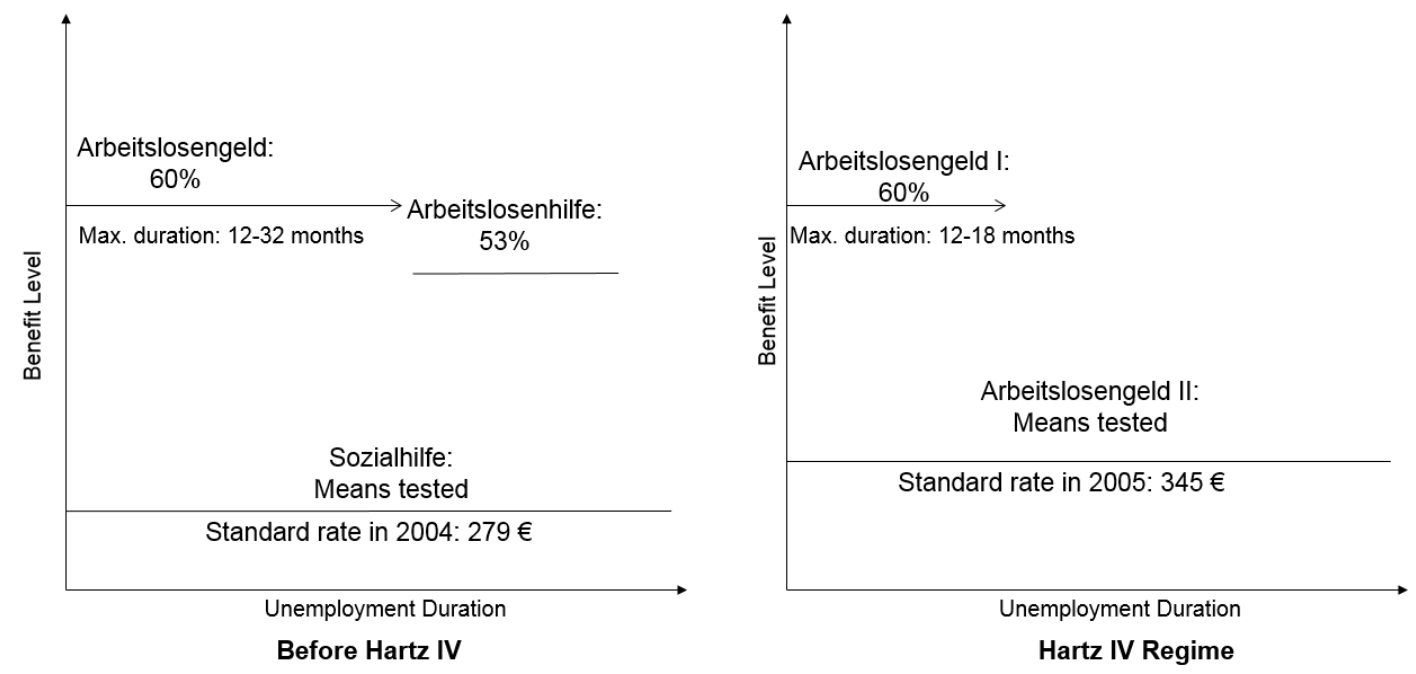

Figure 2: Illustration of the Hartz IV Reform for single households. Source: Own illustration

switched from a system that was proportional to prior earnings to a fixed low-level transfer or because of ineligibility due to high spousal income. The latter faced a large drop because they, too, may have been ineligible for benefits before running down their wealth.

This institutional setting explains why it is difficult to quantify the decline of the replacement rate due to Hartz IV. Some groups faced a strong reduction of the replacement rate. A single median-income earner faced a drop of 69 percent according to the OECD Tax-Benefit Calculator (Seeleib-Kaiser, 2016). By contrast, some low-income households (without wealth) actually saw a slight increase of their replacement rate. It is very difficult to weigh these groups properly because the low-skilled workers are overrepresented in the pool of long-term unemployed and their benefits changed the least with the reform. On the other hand, many high-income workers who have on average short unemployment spells never touch the pool of long-term unemployed. Even if they do, they might not make a claim for benefits because they would not pass the means testing. ${ }^{13}$ Finally, measuring the average decline of the replacement rate is further complicated by the cut in maximum entitlement duration for older workers.

It is therefore not surprising that one of the key reasons for the diverging results in existing macroeconomic studies are different values for the decline of the replacement rate. Krebs/Scheffel (2013) use a decline of 20 percent for the replacement rate of long-term unemployed in their counterfactual simulation, in Krause/Uhlig (2012) the reduction is around 24 percent for low-skilled workers and around 67 percent for high-skilled workers. By contrast, Launov/Wälde (2013) use a decline of 7 percent. Given the mentioned difficulties in quantifying this drop, we use an outcome variable that is directly affected by a decline of the present value of unemployment, namely the share of workers that is selected by firms upon contact.

\footnotetext{
$\overline{13}$ In this case they would not even by counted as unemployed if they did not register with the Federal Employment Agency.
} 


\section{The Model}

We use a version of the Diamond-Mortensen-Pissarides (DMP) model (e.g. Pissarides, 2000: Ch.1) in discrete time. The model is enriched in two dimensions: First, idiosyncratic training costs for new hires, and second, a rich unemployment duration structure for unemployed workers with different contact efficiencies and fixed hiring costs. There is a continuum of workers on the unit interval who can either be employed or unemployed. Unemployed workers randomly search for jobs on a single labour market and receive unemployment compensation $b^{s}$ during the first 12 months of any unemployment spell (i.e. short-term unemployment benefits) and $b_{t}^{l}$ afterwards (i.e. long-term unemployment benefits). Long-term benefits have a time index, as these were changed by the reform. Employed workers can lose their job with constant probability $\phi$. Unemployed workers are indexed by the letter $d$, where $d \in\{0,1, \ldots, 12\}$ denotes the time left in months that a worker is still eligible for short-term unemployment benefits $b^{s}$. Therefore, a worker who has just lost a job receives the index 12 , while a worker indexed by 0 is considered long-term unemployed. There is a fixed number of multi-worker firms on the unit interval indexed by $i$. Firms have to post vacancies in order to get in contact with workers and pay vacancy posting costs $\kappa$ per vacancy. We assume free-entry of vacancies. Contacts between searching workers and firms are established via a standard Cobb-Douglas contact function. While all workers search on the same market, the contact efficiency of workers may depend on the duration of unemployment. In addition, workers vary in the amount of training they require for a specific vacancy. Technically, firms and workers draw a match-specific realisation $\varepsilon$ from an idiosyncratic training costs distribution with density $f(\varepsilon)$ and cumulative density $F(\varepsilon)$. We assume a fixed training cost component $t c^{d}$ that reflects that the average training required upon reemployment depends on the duration of the prior unemployment spell. ${ }^{14}$ This is consistent with the idea that human capital depreciates during unemployment. Only contacts with sufficiently low training costs, $\varepsilon_{i t} \leq \tilde{\varepsilon}_{i t}^{d}$ will result in a hire, where $\tilde{\varepsilon}_{i t}^{d}$ is firm $i$ 's hiring cutoff and $\eta_{i t}^{d}=\eta\left(\tilde{\varepsilon}_{i t}^{d}\right)$ is the firm's selection rate (i.e. the hiring probability for a given contact). Figure 3 illustrates the main features of the model.

Our model is similar to that in Kohlbrecher/Merkl/Nordmeier (2016), to the stochastic job matching model (Pissarides, 2000: chapter 6) or many of the endogenous separation models (e.g. Krause/Lubik, 2007). Chugh/Merkl (2016), Lechthaler/Merkl/Snower (2010), and Sedlaĉek (2014) are further examples of labour selection models. Except for different unemployment durations, which are essential for the reform, we do not model further heterogeneities in our theoretical framework (e.g. permanent skill differentials or wealth differentials among unemployed workers). The reason is that the IAB Job Vacancy Survey does not provide any guidance on the selection rate in these dimensions. Thereby, the results across groups would be driven by modelling and parametrisation choices instead of being disciplined by the data.

\footnotetext{
$\overline{14}$ We assume that the idiosyncratic training cost distribution is the same for all worker types. Equivalently, we could let the mean of the distribution shift with duration of unemployment.
} 


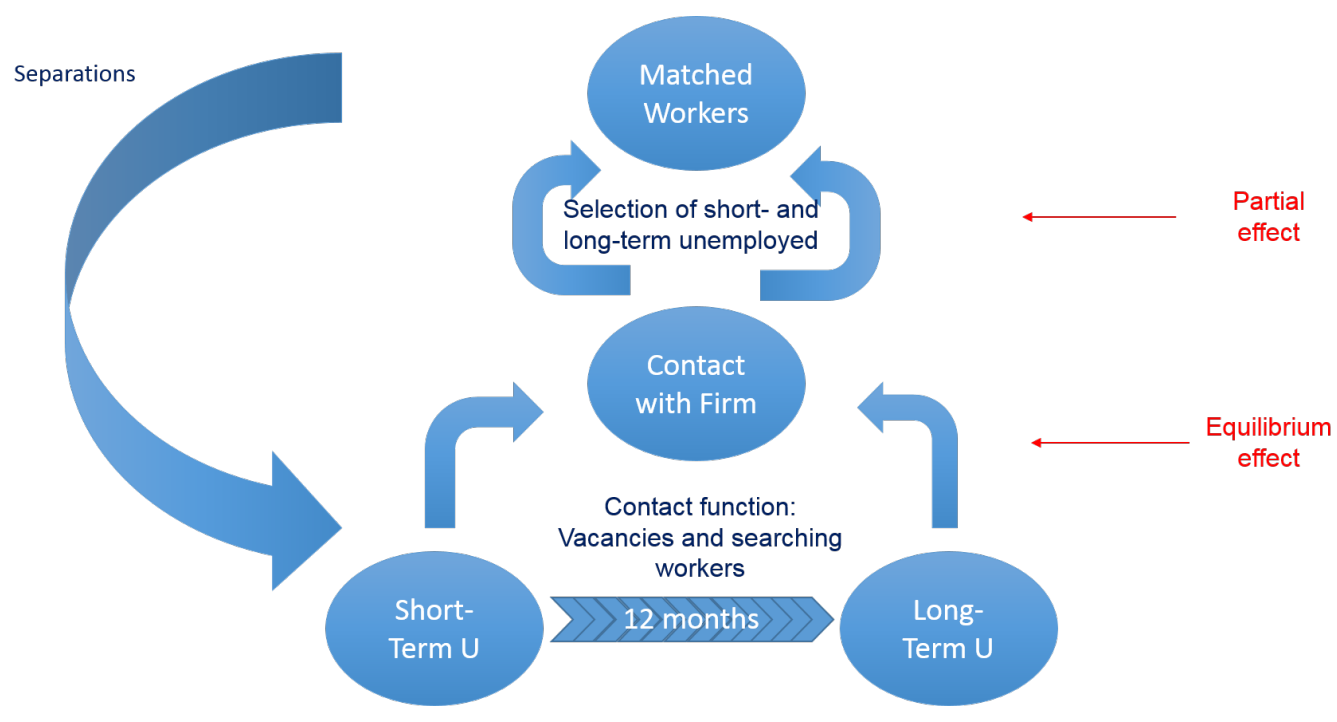

Figure 3: Graphical model description. Source: Own illustration

\subsection{Firm's Problem}

Firms produce with a constant returns technology with labour as the only input. They post vacancies at a fixed cost $\kappa$ per vacancy. Search is random (i.e. undirected). The probability for a firm of hiring an unemployed worker indexed by duration $d$ depends on three factors: the share of unemployed workers indexed by $d$ among all the searching workers $s_{t}^{d}$, their respective search efficiency which translates into different contact probabilities for firms $q_{t}^{d}$, and the firm's selection rate, $\eta_{i t}^{d}=\eta\left(\tilde{\varepsilon}_{i t}^{d}\right)$, which depends on the firm's hiring cutoff $\tilde{\varepsilon}_{i t}^{d}$.

The firm discounts the future with discount factor $\delta$ and chooses employment $n_{i t}$, vacancies $v_{i t}$ and its hiring cutoffs $\tilde{\varepsilon}_{i t}^{d}$ for all $d \in\{0,1, \ldots, 12\}$ to maximise the following intertemporal profit function:

$$
E_{0}\left\{\sum_{t=0}^{\infty} \delta^{t}\left[a_{t} n_{i t}-w_{i t}^{I}(1-\phi) n_{i, t-1}-\kappa v_{i t}-v_{i t} \sum_{d=0}^{12} s_{t}^{d} q_{t}^{d} \eta_{i t}^{d}\left(\bar{w}_{i t}^{d}+\bar{H}_{i t}^{d}+t c^{d}\right)\right]\right\}
$$

subject to the evolution of the firm's employment stock and the firm's selection rate for workers with duration index $d$ in every period:

$$
\begin{gathered}
n_{i t}=(1-\phi) n_{i, t-1}+v_{i t} \sum_{d=0}^{12} s_{t}^{d} q_{t}^{d} \eta_{i t}^{d}, \\
\eta_{i t}^{d}=\int_{-\infty}^{\tilde{\varepsilon}_{i t}^{d}} f(\varepsilon) d \varepsilon \quad \forall d .
\end{gathered}
$$

Here and in the following $a_{t}$ stands for aggregate productivity, $n_{i t}$ firm-specific employment, $t c^{d}$ are fixed training costs, $w_{i t}^{I}$ is the wage for incumbent workers (who do not require any training), and $\bar{w}_{i t}^{d}$ and $\bar{H}_{i t}^{d}$ denote firm $i$ 's expectation of the wage and the idiosyncratic 
training costs realisation conditional on hiring. ${ }^{15}$

Let $\pi_{i t}^{d}$ and $\pi_{i t}^{I}$ denote the firm's discounted profit at time $t$ for a newly hired worker with remaining eligibility for short-term unemployment benefits $d$ and for an incumbent worker (indexed by $I$ ):

$$
\begin{gathered}
\pi_{i t}^{d}\left(\varepsilon_{i t}\right)=a_{t}-w_{i t}^{d}\left(\varepsilon_{i t}\right)-\varepsilon_{i t}-t c^{d}+\delta(1-\phi) E_{t} \pi_{i, t+1}^{I}, \\
\pi_{i t}^{I}=a_{t}-w_{i t}^{I}+\delta(1-\phi) E_{t} \pi_{i, t+1}^{I} .
\end{gathered}
$$

Taking first order conditions of equation (1) with respect to firm-specific employment $n_{i t}$, vacancies $v_{i t}$, and the hiring cutoffs $\tilde{\varepsilon}_{i t}^{d}$ and rearranging yields the following optimality conditions for the firm:

$$
\tilde{\varepsilon}_{i t}^{d}=a_{t}-\tilde{w}_{i t}^{d}-t c^{d}+\delta(1-\phi) E_{t} \pi_{i, t+1}^{I} \quad \forall d
$$

and

$$
\kappa=\sum_{d=0}^{12} s_{t}^{d} q_{t}^{d} \eta_{i t}^{d} \bar{\pi}_{i t}^{d} .
$$

Note that all variables with a "tilde" sign are evaluated at the cutoff training costs $\tilde{\varepsilon}_{i t}^{d}$ while variables with a "bar" correspond to the expectation of the respective variable conditional on hiring (i.e. the evaluation of the variable at the conditional mean of idiosyncratic training costs and/or wages).

As firms are ex-ante identical, they all choose the same hiring cutoff and hence selection probability. We can therefore write:

$$
\tilde{\varepsilon}_{t}^{d}=a_{t}-\tilde{w}_{t}^{d}-t c^{d}+\delta(1-\phi) E_{t} \pi_{t+1}^{I} \quad \forall d,
$$

and

$$
\kappa=\sum_{d=0}^{12} s_{t}^{d} q_{t}^{d} \eta_{t}^{d} \bar{\pi}_{t}^{d}
$$

with

$$
\pi_{t}^{d}\left(\varepsilon_{t}\right)=a_{t}-w_{t}^{d}\left(\varepsilon_{t}\right)-\varepsilon_{t}-t c^{d}+\delta(1-\phi) E_{t} \pi_{t+1}^{I},
$$

and

$$
\pi_{t}^{I}=a_{t}-w_{t}^{I}+\delta(1-\phi) E_{t} \pi_{t+1}^{I}
$$

Finally, the economy-wide selection rate for workers with duration index $d$ is

$$
\eta_{t}^{d}=\int_{-\infty}^{\tilde{\varepsilon}_{t}^{d}} f(\varepsilon) d \varepsilon \quad \forall d
$$

15 More specifically, $\bar{w}_{i t}^{d}=\frac{\int_{-\infty}^{\tilde{\varepsilon}_{i t}^{d}} w_{i t}^{d}(\varepsilon) f(\varepsilon) d \varepsilon}{\eta_{i t}^{d}}$ and $\bar{H}_{i t}^{d}=\frac{\int_{-\infty}^{\tilde{\varepsilon}_{i t}^{d}} \varepsilon f(\varepsilon) d \varepsilon}{\eta_{i t}^{d}}$. 
and the conditional mean (and expectation) of idiosyncratic training costs is

$$
\bar{H}_{t}^{d}=\frac{\int_{-\infty}^{\tilde{\varepsilon}_{t}^{d}} \varepsilon f(\varepsilon) d \varepsilon}{\eta_{t}^{d}} \quad \forall d .
$$

\subsection{Worker's Problem}

Workers have linear utility over consumption and discount the future with discount factor $\delta$. Once separated from a job, a worker is entitled to 12 months of short-term unemployment benefits $b^{s}$ and long-term unemployment benefits $b_{t}^{l}$ afterwards, with $b^{s}>b_{t}^{l}$.

The value of unemployment therefore depends on the remaining months a worker is eligible for short-term unemployment benefits. For a short-term unemployed (i.e. $d \in\{1, \ldots, 12\}$ ) the value of unemployment is given by:

$$
U_{t}^{d}=b^{s}+\delta E_{t}\left[p_{t+1}^{d-1} \eta_{t+1}^{d-1} \bar{V}_{t+1}^{d-1}+\left(1-p_{t+1}^{d-1} \eta_{t+1}^{d-1}\right) U_{t+1}^{d-1}\right] .
$$

In the current period, the short-term unemployed receives benefits $b^{s}$. In the next period, she either finds a job or remains unemployed. In the latter case the time left in short-term unemployment $d$ is reduced by a month. The probability of finding employment in the next period will depend on the next period's contact probability and selection rate, which both depend on unemployment duration at that point.

After 12 months of unemployment the worker receives the lower long-term unemployment benefits $b_{t}^{l}$ indefinitely or until she finds a job:

$$
U_{t}^{0}=b_{t}^{l}+\delta E_{t}\left[p_{t+1}^{0} \eta_{t+1}^{0} \bar{V}_{t+1}^{0}+\left(1-p_{t+1}^{0} \eta_{t+1}^{0}\right) U_{t+1}^{0}\right] .
$$

The value of work for an entrant depends through the wage on the remaining months she is eligible for short-term benefits and on the realisation of the idiosyncratic training cost:

$$
V_{t}^{d}\left(\varepsilon_{t}\right)=w_{t}^{d}\left(\varepsilon_{t}\right)+\delta E_{t}\left[(1-\phi) V_{t+1}^{I}+\phi U_{t+1}^{I}\right] \quad \forall d .
$$

Following our previous notation, $\bar{V}_{t}^{d}$ corresponds to the evaluation of $V_{t}^{d}\left(\varepsilon_{t}\right)$ at the conditional expectation of $\varepsilon_{t}$. We allow for the possibility of immediate rehiring. The resulting value of work for an incumbent worker $I$ is:

$$
V_{t}^{I}=w_{t}^{I}+\delta E_{t}\left[(1-\phi) V_{t+1}^{I}+\phi U_{t+1}^{I}\right]
$$

where $U_{t}^{I}$ denotes the outside option for an incumbent worker, in case that wage negotiations fail or she is exogenously separated from her job:

$$
U_{t}^{I}=p_{t}^{12} \eta_{t}^{12} \bar{V}_{t}^{12}+\left(1-p_{t}^{12} \eta_{t}^{12}\right) U_{t}^{12}
$$




\subsection{Contacts}

Contacts between searching workers and firms are established via a Cobb-Douglas, constant returns to scale (CRS) contact function

$$
c_{t}^{d}=\mu_{t}^{d} v_{t}^{\gamma} u s_{t}^{1-\gamma} \quad \forall d
$$

where $u s_{t}$ are the number of searching workers at the beginning of period $t, v_{t}$ is the vacancy stock, $c_{t}^{d}$ is the number of contacts in period $t$ made with unemployed with duration $d$, and $\mu_{t}^{d}$ is the contact efficiency that depends on the duration of unemployment. The contact probability for a worker and for a firm are therefore:

$$
p_{t}^{d}\left(\theta_{t}\right)=\mu_{t}^{d} \theta_{t}^{\gamma} \quad \forall d,
$$

and

$$
q_{t}^{d}\left(\theta_{t}\right)=\mu_{t}^{d} \theta_{t}^{\gamma-1}
$$

with

$$
\theta_{t}=\frac{v_{t}}{u s_{t}}
$$

\subsection{Unemployment Dynamics}

As the total labour force is normalised to one, the total number of unemployment (and also the unemployment rate) in period $t$ after matching has taken place is the sum over all unemployment states $(d \in\{0, \ldots, 12\})$ :

$$
u_{t}=\sum_{d=0}^{12} u_{t}^{d} .
$$

Employment in period $t$ is thus given by

$$
u_{t}=1-n_{t}
$$

The number of unemployed with 12 remaining months of short-term benefits is given by the workers that have been separated at the end of last period and were not immediately rehired:

$$
u_{t}^{12}=\phi\left(1-p_{t}^{12} \eta_{t}^{12}\right) n_{t-1} .
$$

The law of motion for unemployment with remaining eligibility of short-term unemployment benefits $d \in\{1, \ldots, 11\}$ is:

$$
u_{t}^{d}=\left(1-p_{t}^{d} \eta_{t}^{d}\right) u_{t-1}^{d+1},
$$

and the pool of long-term unemployed consists of the unemployed whose short-term benefit eligibility has just expired as well as previous period's long-term unemployed that have not been matched:

$$
u_{t}^{0}=\left(1-p_{t}^{0} \eta_{t}^{0}\right)\left(u_{t-1}^{1}+u_{t-1}^{0}\right) .
$$

We can now define the number of searching workers at the beginning of period $t$ (before 
matching has taken place):

$$
u s_{t}=\phi n_{t-1}+u_{t-1} .
$$

The share of searching workers with remaining short-term unemployment eligibility of $d$ months among all searchers is therefore:

$$
s_{t}^{12}=\frac{\phi n_{t-1}}{u s_{t}}
$$

for newly separated workers,

$$
s_{t}^{d}=\frac{u_{t-1}^{d+1}}{u s_{t}}
$$

for $d \in\{1, \ldots, 11\}$ and

$$
s_{t}^{0}=\frac{u_{t-1}^{1}+u_{t-1}^{0}}{u s_{t}}
$$

for long-term unemployed.

\subsection{Wages}

In the main part of the paper, we assume individual Nash bargaining for both new and existing matches. Workers and firms bargain over the joint surplus of a match, where workers' bargaining power is $\alpha$ and firms' bargaining power is $(1-\alpha)$. The Nash bargained wages therefore solve the following problems:

$$
w_{t}^{d}\left(\varepsilon_{t}\right) \in \arg \max \left(V_{t}^{d}\left(\varepsilon_{t}\right)-U_{t}^{d}\right)^{\alpha}\left(\pi_{t}^{d}\left(\varepsilon_{t}\right)\right)^{1-\alpha} \quad \forall d
$$

for newly hired workers with prior duration index $d$ and

$$
w_{t}^{I} \in \arg \max \left(V_{t}^{I}-U_{t}^{I}\right)^{\alpha}\left(\pi_{t}^{I}\right)^{1-\alpha}
$$

for an incumbent worker. Note that the individually bargained wage will depend on the idiosyncratic training cost component as the latter enters firms' profits $\pi_{t}^{d}(\varepsilon) .{ }^{16}$ In Appendix C.1 we show results for the polar opposite case when wages are bargained collectively.

\subsection{Labour Market Equilibrium}

Given initial values for all states of unemployment $u_{t-1}^{d}$ with $d \in\{0, \ldots, 12\}$ and employment $n_{t-1}$ as well as processes for productivity and long-term unemployment benefits $\left\{a_{t}, b_{t}^{l}\right\}_{t=0}^{+\infty}$, the labour market equilibrium is a sequence of allocations $\left\{n_{t}, u_{t}, u s_{t}, v_{t}, \theta_{t}, u_{t}^{d}, s_{t}^{d}, p_{t}^{d}, q_{t}^{d}, \tilde{\varepsilon}_{t}^{d}, \eta_{t}^{d}, \bar{H}_{t}^{d}, \pi_{t}^{I}, \bar{\pi}_{t}^{d}, V_{t}^{I}, \bar{V}_{t}^{d}, \tilde{V}_{t}^{d}, U_{t}^{I}, U_{t}^{d}, w_{t}^{I}, \bar{w}_{t}^{d}, \tilde{w}_{t}^{d}\right\}_{t=0}^{+\infty}$

\footnotetext{
${ }^{16}$ Due to the training costs in the first period, the wage for entrants is smaller than the wage for incumbents in our bargaining setup. However, the net present value of the match for workers and firms at the time of hiring is equivalent to a wage contract where the training costs in the wage are spread over the entire employment spell. Results are available on request.
} 
for all durations $d \in\{0, \ldots, 12\}$ that satisfy the following equations: the definition of employment (24), unemployment (23) and searching workers (28), the free-entry condition for vacancies (9), market tightness (22), unemployment (25) - (27), the shares of searching workers (29) - (31), the contact rates for workers (20) and firms (21), the hiring cutoffs (8), selection rates (12), conditional expectation of idiosyncratic hiring costs (13), the definition of profits for entrants $(10)$ and incumbents (11), the value of a job for entrants (16) and incumbents (17), the value of unemployment (14), (15), and (18), and the definition of wages (32) and (33), where wages, the value of work for entrant workers as well as firms' profits for new hires are evaluated either at the cutoff and/or the conditional expectation of idiosyncratic training costs.

\section{Empirical Strategy}

The German Hartz IV reform reduced the replacement rate for long-term unemployed. Less generous unemployment benefits decrease workers' fallback option in our model. The closer unemployed workers get to the expiration of short-term benefits, the lower will be the value of unemployment and the lower will be their reservation wage. This leads to lower bargained wages. One of the key differences of our model relative to the plain vanilla search and matching model (e.g. Pissarides, 2000: Ch.1) is that matching has two components and that two effects are initiated due to a decline in benefits. First, workers and firms have to get in contact with one another, where $p_{t}$ denotes workers' contact rate. Lower unemployment benefits lead to more vacancy posting by all firms due to higher expected profits. In equilibrium, this leads to a higher tightness in the market and thus a higher contact rate for workers. We call this mechanism the equilibrium effect. Second, upon contact a certain fraction of workers is selected at the firm level, where $\eta_{t}$ denotes the selection rate. With lower unemployment benefits and hence lower wages, firms are willing to select workers with higher idiosyncratic training costs at the margin. Thus, the selection rate increases. As this effect takes place at the worker-firm level, we call this mechanism the partial effect.

As the aggregate contact and selection rate are roughly multiplicative in our model $\left(j f r_{t} \approx\right.$ $\left.p_{t} \eta_{t}\right):{ }^{17}$ we can express the job-finding rate as the sum of the contact rate and the selection rate in terms of log-deviations (denoted with hats):

$$
j \hat{f} r_{t} \approx \hat{p}_{t}+\hat{\eta}_{t},
$$

where $\hat{p}_{t}$ corresponds to the equilibrium effect and $\hat{\eta}$ corresponds to the partial effect. For the sake of simplicity, we will refer to the response of the selection rate to a benefit change as the partial effect. This is slightly inaccurate wording, as there is a small, negative feedback effect from tightness on the selection rate.

\footnotetext{
17 Note that this connection holds with equality for each duration group $j f r_{t}^{d}=p_{t}^{d} \eta_{t}^{d}$. In aggregate, it only holds with equality on impact when the shares of unemployed workers in different duration groups are equal to the steady state shares. During the adjustment dynamics, composition effects start playing a role. See discussion in Section 6.
} 
This section proceeds in four steps. We will first describe the construction of an empirical measure of the selection rate. We will then demonstrate how the combination of model and data informs us about the partial and equilibrium effect of a benefit reform. In steps three and four, we will describe the empirical estimation and implementation for partial and equilibrium effect.

\subsection{Measuring Selection}

A core innovation of our paper is the construction of an empirical time series for the selection rate. Our approach is closely related to Davis/Faberman/Haltiwanger (2013) and Gavazza/Mongey/Violante (2018). Davis/Faberman/Haltiwanger (2013) show that firms use additional margins to vacancy posting to adjust hiring over the business cycle. Labour selection represents one of these. We are the first to provide direct evidence on this channel.

As our choice of measurement is informed by the model, it is useful to think about the role of selection from the model's point of view. The selection rate corresponds to the share of workers that is hired upon meeting a firm or, put differently, the probability that a worker that gets in contact with a firm, is hired. Therefore, the selection rate corresponds to the inverse of the average number of contacts a firm makes until it realises a hire. Figure 4 shows the response of the total number of contacts in the model economy and the number of contacts for the last hire in response to a negative benefit shock in a model simulation. ${ }^{18}$ The total number of contacts first goes up after the decline of benefits because workers' contact rate increases due to more vacancy posting (the equilibrium effect). In the medium run, it converges to a new steady state below the initial level because the pool of unemployed declines over time. Very importantly, the number of contacts per hire, which equals the inverse of the selection rate, has completely different dynamics. It drops on impact and stays at a permanently lower level. For example, when a multi-worker firm has a selection probability of 50 percent, it makes on average two contacts per hire. When the firm selects only 33 percent of workers, it requires on average three contacts until hiring. As firms select a larger fraction of contacts when benefits - and hence workers' outside option - fall, the number of contacts per hire goes down. Note that if the selection rate was constant, as standard in many search and matching models, the number of matches and the number of contacts in the economy would rise in equal proportion and the number of contacts per hire would not change. With an increased selection rate, however, hires rise more than proportionally which is reflected in a lower number of contacts per hire.

Based on these insights, we are the first to construct a time series for selection over the business cycle. For this purpose, we use the IAB Job Vacancy Survey which is an annual representative survey of up to 14,000 German establishments. ${ }^{19}$ Firms are asked about the number of suitable applicants for their last realised hire. The question is well in line

\footnotetext{
${ }^{18}$ Note that the IRFs are based on the calibration as described below. At this stage, we show them for illustration purposes and only discuss the qualitative response.

${ }^{19}$ For more information on the IAB Job Vacancy Survey, see Appendix B.1
} 

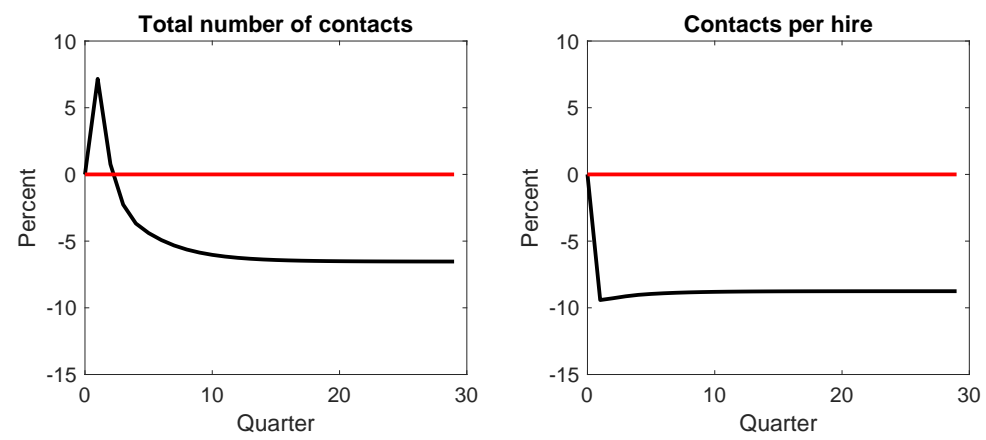

Figure 4: Total number of contacts and contacts per hire in response to a reduction of the replacement rate for long-term unemployed in the baseline calibration.

with our model. Given that firms are asked about the number of suitable applicants ${ }^{20}$ firms must have screened these candidates in some way (e.g. by checking the application package or by inviting the applicant for an interview). The number of suitable applicants therefore is a natural proxy for the number of contacts a firm has made for the last hire. Thus, we can calculate the average probability of a worker (who got in contact with a firm) to be selected as the inverse of the number of suitable applicants for the last hire. Note that the IAB Job Vacancy Survey is a repeated cross-section and hence does not allow to perform firm-level panel regressions. Thus, we can only run regressions at aggregated levels. Using representative survey weights for the last hire, we therefore construct annual selection rate time series on the national (West Germany), state and industry level from 1992 to $2015 .^{21}$

Figure 5 shows the movement of the job-finding rate, selection rate and market tightness (defined as vacancies over unemployment) from 1992 to 2015. We normalised all three time series to an average of one to improve the visibility of relative movements. As predicted by theory, both the job-finding rate and the selection rate move procyclically with market tightness, although the latter shows much stronger fluctuations. This is well in line with our model. Kohlbrecher/Merkl/Nordmeier (2016) show that the selection rate comoves procyclically (but less than proportionally) with market tightness over the business cycle in a selection model. Note that in the standard model without selection, the share of selected applicants would be constant over the business cycle as the number of contacts and the number of hires would comove one-to-one.

In addition, the descriptive evidence is well in line with the idea of endogenous recruiting intensity by Davis/Faberman/Haltiwanger (2013) and Gavazza/Mongey/Violante (2018). Labour selection may be one important dimension of recruiting intensity. Figure 5 shows that firms increase their labour selection rate in labour market upswings and reduce it in labour market downswings. This illustrates that they do not only use the vacancy margin over the business cycle. They also become more or less selective in terms of their hiring

${ }^{20}$ In the most recent waves of the survey, firms are also asked about the overall number of applicants. This number is on average substantially higher.

${ }^{21}$ We restrict the analysis to West Germany for two reasons. First, the conditions in East Germany were driven by the transformation to a market economy in the 1990s. Labour market turnover rates in East Germany have converged to those of West Germany only by 2008 (see Fuchs et al., 2018।. Second, the number of establishments in the sample is very small in the early 1990s. 
behaviour.

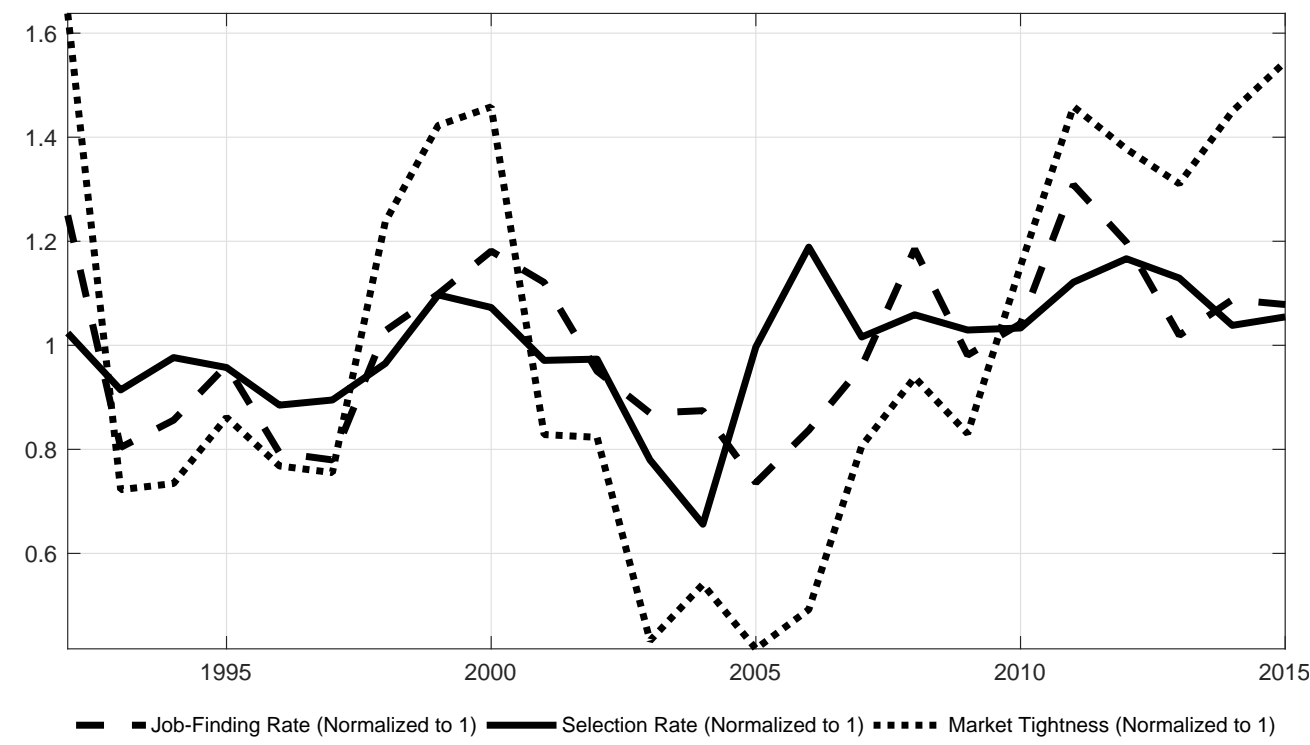

Figure 5: German labour market dynamics, 1992-2015. Source: Own calculations based on data from the German Federal Labour Office, the IAB Job Vacancy Survey and the IEB.

\subsection{Linking the Model to the Data}

How are these time series helpful for our identification? Ideally, we would be able to identify the reaction of the job-finding rate with respect to benefit changes directly, namely $\partial j \hat{f} r_{t} / \partial \hat{b}_{t}$. Besides the usual econometric issues, this is particularly complicated for the Hartz IV reform. First, several other labour market reforms (namely, Hartz I to III) were implemented in 2003 and 2004 briefly before the Hartz IV reform. These may have affected the job-finding rate through increases in contact efficiency (see e.g. Launov/Wälde 2016). Thus, based on time series for the job-finding rate it is very difficult to disentangle the effects of the different reform steps. Second, there is a severe structural break in the unemployment series in 2005 as a direct consequence of the reform. In order to be eligible for benefits after 2005 , former recipients of social assistance who were able to work had to register as unemployed. Those people had not been counted as unemployed under the old system. As the adjustment to the new definition took place over several months and the new registrants had very different characteristics, it is very hard to cleanly control for the change in measurement during that time. ${ }^{22}$ Finally, it is important to note that unemployment in Germany is based on registration with the Federal Employment Office and not self-reported job search. Unemployed workers not eligible for long-term benefits after the reform may have decided not to register while still searching. Therefore, only looking at unemployment to employment transitions might miss some of the employment effects if formerly unemployed workers found jobs after deregistering. Recent evidence on labour market flows around the time of the Hartz reforms by Carrillo-Tudela/Launov/Robin (2018) suggests that this channel indeed played an important role.

\footnotetext{
${ }^{22}$ In a robustness check in the Appendix, we control for the structural break in the job-finding rate using two
} different methodologies. 
To circumvent these problems, we apply a novel empirical strategy that combines insights from our theoretical model with our unique time series and panel data. We start with the observation that we can decompose the reaction of the job-finding rate to benefit changes into changes of the contact rate and selection rate:

$$
\frac{\partial j \hat{f} r_{t}}{\partial \hat{b}_{t}} \approx \frac{\partial \hat{p}_{t}}{\partial \hat{b}_{t}}+\frac{\partial \hat{\eta}_{t}}{\partial \hat{b}_{t}}
$$

Unfortunately, we cannot provide any estimates for the reaction of the contact rate, $\partial \hat{p}_{t} / \partial \hat{b}_{t}$, because there is no direct and independent measure available. Our identification therefore consists of two steps. First, we will directly estimate the partial effect $\left(\partial \hat{\eta}_{t} / \partial \hat{b}_{t}\right)$ based on the reaction of the selection rate at the time of the Hartz IV reform. As the selection rate is based on an establishment survey, it is not affected by the structural measurement break in the unemployment series in 2005.

Second, we use an indirect inference method to estimate the equilibrium effect, i.e. the response of the contact rate $\partial \hat{p}_{t} / \partial \hat{b}_{t}$. With an estimate of the partial effect (i.e. selection) with respect to benefits $\left(\partial \hat{\eta}_{t} / \partial \hat{b}_{t}\right)$, all we need to know is how important the response of the contact rate is relative to the response of the selection rate to a benefit shock. Through the lens of our model, the relative contribution of the contact rate and the selection rate to the transmission of aggregate shocks (in our case, an aggregate productivity shock) and benefit changes is equivalent. ${ }^{23}$ More precisely, in our model the following relation is true:

$$
\frac{\partial \hat{p}_{t} / \partial \hat{b}_{t}}{\partial \hat{\eta}_{t} / \partial \hat{b}_{t}} \approx \frac{\partial \hat{p}_{t} / \partial \hat{\theta}_{t}}{\partial \hat{\eta}_{t} / \partial \hat{\theta}_{t}} .
$$

We can therefore use the business cycle behaviour of the job-finding rate and the selection rate to infer the relative importance of the equilibrium effect. To be more precise, we will use the following decomposition:

$$
\frac{\partial j \hat{f} r_{t}}{\partial \hat{\theta}_{t}} \approx \frac{\partial \hat{p}_{t}}{\partial \hat{\theta}_{t}}+\frac{\partial \hat{\eta}_{t}}{\partial \hat{\theta}_{t}}
$$

The job-finding rate over the business cycle is a function of market tightness and it can be decomposed into the comovement of the contact rate and the selection with respect to market tightness. Thus, in order to identify the relative importance of the equilibrium effect over the business cycle $\left[\partial \hat{p}_{t} / \partial \hat{\theta}_{t}\right] /\left[\partial \hat{\eta}_{t} / \partial \hat{\theta}_{t}\right]$, we estimate the elasticity of the job-finding rate with respect to market tightness and the elasticity of the selection rate with respect to market tightness. By equation (37), these two measures pin down the elasticity of the contact rate with respect to market tightness, which in the model is given by the parameter $\gamma$ (see equations (19) and (20)).

Note that our model predicts a positive elasticity of the selection rate with respect to market tightness. This does not reflect a direct link from tightness to selectior ${ }^{24}$ but a joint comovement in response to business cycle shocks (productivity shocks in our case). Kohlbrecher/

\footnotetext{
${ }^{23}$ This can be shown numerically and also analytically in a simplified version of the model. Results are available on request.

${ }^{24}$ As argued, the direct effect from tightness on selection is negative although quantitatively small.
} 
Merkl/Nordmeier (2016) show in a similar model structure that this joint comovement has an analytical expression in the steady state, namely: ${ }^{25}$

$$
\frac{\partial \ln \eta}{\partial \ln \theta}=\frac{f(\tilde{\varepsilon})}{\eta}\left(\tilde{\varepsilon}-\frac{\int_{-\infty}^{\tilde{\varepsilon}} \varepsilon f(\varepsilon) d \varepsilon}{\eta}\right)>0 .
$$

Two implications follow: First, the elasticity of the selection rate with respect to market tightness is directly tied to the shape of the training cost distribution at the hiring cutoff. Indeed, this target jointly with a target for the mean selection rate will uniquely pin down the parameters of the training cost distribution. Second, if both the selection rate and the contact rate move procyclically over the business cycle, the elasticity of each variable with respect to market tightness must be strictly smaller than the estimated elasticity of the job-finding rate with respect to market tightness. ${ }^{26}$

\subsection{Determining the Partial Effect}

Our new time series for the selection rate allows us to estimate the partial effect for the Hartz IV reform. Visual inspection of Figure 5 shows that the selection rate - in line with our model prediction - increased substantially in 2005 when the Hartz IV reform was implemented. We have argued before that it is very difficult to estimate the effects of Hartz IV based on the time-series data on unemployment and the job-finding rate. In the following, we provide several arguments why these caveats do not apply to the selection rate. First, the selection rate is derived from the IAB Job Vacancy Survey and is therefore not affected by the change of registration requirements/incentives and the resulting structural break in the unemployment series in the administrative data. In addition, the selection rate is not directly affected by labour market reforms that improve matching efficiency. Launov/Wälde (2016), for example, argue that the reform of the Federal Employment Agency (Hartz III reform in 2004) has increased the matching efficiency in Germany substantially and was therefore a key contributor for the decline of unemployment in Germany. In our model, however, improved matching efficiency does not directly impact the selection rate, as selection takes place after contacts between workers and firms have been established. While there is an indirect effect though bargained wages, it is negative and small (see Figure C.2 in the Appendix). In this case, we obtain a lower bound when we estimate the partial effect. One might also object that the selection rate could be affected by changes in workers' search behaviour caused by the reform. A common perception is that under the new and stricter benefit regime workers are required to document search effort, e.g. in forms of written applications. Two scenarios are possible: Either, these forced applications are not meaningful and do not make it into the pool of suitable applicants. In this case the selection rate would be unaffected. Or the number of suitable applicants increases which could lower the measured selection rate. ${ }^{27}$ Again, if we find an increase of the selection rate in response to the reform, it is downward biased. Finally, it is worthwhile pointing out that the reform

\footnotetext{
25 This expression is only exactly true in the steady state of a model with a constant contact rate.

${ }^{26}$ We refer the reader to Kohlbrecher/Merkl/Nordmeier 12016, for analytical proofs and a more detailed discussion of the above decomposition.

27 This is an empirical argument. Through the lens of our model, contacts and hires would increase in equal proportion in this case and leave our measure of selection unaffected.
} 
introduced a permanent change in policy. For all these reasons, it is a valid strategy to estimate the reform effect with a simple shift dummy. Of course, while the selection rate is not immediately affected by changes in tightness (equilibrium effect), there is a small feedback effect through the influence of contact rates on wages. We show that the change of the selection rate is barely affected if we control for tightness in our estimations.

In order to obtain the partial effect of Hartz IV on the selection rate, we run versions of the following regression:

$$
\ln \eta_{t}=\beta_{0}+\beta_{1} D_{t}^{\text {Hartz } I V}+\beta_{2} B I_{t}+\beta_{3} X_{t}+\nu_{t} .
$$

The dependent variable $\ln \eta_{t}$ is the logarithm of the selection rate, which is regressed on a shift dummy that takes the value of one from 2005 onward $\left(D_{t}^{\operatorname{Hartz} I V}\right)$ to measure the differences in the selection rate before and after Hartz IV. In order to disentangle the Hartz IV effect from the business cycle, our regression contains business cycle indicators (BI). In our baseline estimation, we use value added growth for West Germany. ${ }^{28}$ In addition, we also control for potential feedback effects of market tightness $\theta_{t}$ on the selection rate. ${ }^{29}$ Furthermore, $X_{t}$ denotes controls which we add in robustness checks, and $\nu_{t}$ is the error term.

Due to data availability, we perform the baseline estimation on an annual basis for the sample range 1992 to 2015. In a robustness check, we also perform a fixed-effects panel estimation on West German state and industry level, which yields very similar results.

Table 1 shows that conditional on value added growth the aggregate selection rate has increased by 14 percent after the Hartz IV reform. If we additionally control for market tightness, the coefficient is slightly smaller (13 percent). ${ }^{30}$ The estimated coefficients are statistically significant at the 1 percent level. In a robustness check, we estimate equation (39) with market tightness as business cycle indicator. The aggregate increase of the selection rate after the Hartz IV reform is of similar magnitude (see Table D.1).

Of course, our estimation does not allow us to causally link this effect to the reform but documents a strong positive comovement. In the above discussion, we have already ruled out several alternative explanations for this sharp increase of the selection rate. In addition, a number of robustness checks support our result that the observed increase of the selection rate is indeed linked to the benefit reform. In columns 3 and 4 of Table 1, we show that the results are very similar if we disaggregate by state and industry and use a panel fixed-effects estimator. Moreover, our results are robust if we control for the share of vacancies for low-qualification jobs and the share of long-term unemployed in the pool of unemployment (see columns 5 and 6 in Table 1). ${ }^{31}$

\footnotetext{
${ }^{28}$ We use value added because we have constrained ourselves to West Germany where GDP is not readily available. Using GDP growth for entire Germany as an alternative business cycle indicator leaves our results unaffected.

${ }^{29}$ As the policy change is permanent, effects of future profits are directly reflected in the current level of tightness.

30 This is in line with our model that predicts a small negative feedback effect of tightness on the selection rate.

31 It could be the case that the pool of the unemployed or the types of vacancies posted change due to the
} 
Could the increase in the selection rate capture some general trend in the economy unrelated to the labour market reform? In order to illustrate that our Hartz IV-dummy effect is no coincidence, we perform several regressions with placebo shift-dummies in the years before and after the reform. Figure 6 clearly supports our view that the jump of the selection rate took place in 2005 , the year of the reform. The shift dummy starts being statistically different from zero from 2005 onwards. This is completely in line with our theoretical framework, which predicts that the selection rate increases on a permanent basis once the Hartz IV labour market reform was implemented. In addition, the significance of the shift dummy from 2005 onwards shows that the increase of the selection rate cannot be attributed to earlier Hartz reforms (I to III) or the wage moderation starting in the early 2000 s.

Figure E.4 in Appendix E shows further that the increase of the selection rate between 2004 and 2005 was largest for workers in the middle of the skill distribution. This is in line with our expectation. Compared to workers in the middle of the skill distribution, low-skilled workers faced a moderate decline of the replacement rate due to the Hartz IV reform (see Section 2), while high-skilled workers usually face short unemployment spells and therefore a lower risk of becoming long-term unemployed. Thus, medium-skilled workers were hit hardest by the Hartz IV reform and thereby reacted most in terms of the selection rate. While we agree that it would be desirable to study the cross-sectional response of the selection rate in more detail, we are limited by information provided in the data. Information on skills (for the selection rate) is for example not available for a longer time series.

Before we continue our discussion, let us briefly comment on the estimated results for the business cycle indicators. The selection rate comoves positively with value added growth. However, the estimated coefficient on value added growth is not statistically significant in Table 1. Two comments are in order: First, Figure 7 shows that real GDP dropped by around 5 percent during the Great Recession, while the labour market barely reacted. This phenomenon is known as the German "labour market miracle" (see Burda/Hunt, 2011). Not surprisingly, this phenomenon reduces the statistical significance of value added growth in our estimations. Second, the comovement between the selection rate and market tightness (which we use to control for feedback effects) is statistically significant at the 1 percent level because market tightness represents the state of the labour market much better than value added. This is very much in line with our model that predicts a positive comovement of the selection rate with market tightness (see equation (38)). Controlling for tightness in addition to value added growth (see column 2) does not change the estimated coefficient on the Hartz IV dummy by much.

reform and over the business cycle. 
Table 1: Estimates of the partial effect, results for West Germany, 1992-2015.

\begin{tabular}{|c|c|c|c|c|c|c|}
\hline & \multicolumn{6}{|c|}{ Dependent variable: } \\
\hline & \multirow{2}{*}{\multicolumn{2}{|c|}{ OLS }} & \multicolumn{2}{|c|}{ log(selection rate) } & & \\
\hline & & & & $\begin{array}{l}\text { nel } \\
\text { ear }\end{array}$ & \multicolumn{2}{|c|}{ OLS } \\
\hline & $\begin{array}{l}\text { Aggregate West Germany } \\
\text { (1) }\end{array}$ & $\begin{array}{l}\text { Aggregate West Germany } \\
\text { (2) }\end{array}$ & $\begin{array}{l}\text { State Level } \\
\text { (3) }\end{array}$ & $\begin{array}{l}\text { Industry Level } \\
\text { (4) }\end{array}$ & $\begin{array}{l}\text { Aggr.: Low Qualification } \\
\text { (5) }\end{array}$ & $\begin{array}{c}\text { Aggr.: Long-term } U \\
(6)\end{array}$ \\
\hline Hartz IV Dummy & $\begin{array}{c}0.14^{* * *} \\
(0.03)\end{array}$ & $\begin{array}{l}0.13^{* * *} \\
(0.04)\end{array}$ & $\begin{array}{l}0.12^{* * *} \\
(0.03)\end{array}$ & $\begin{array}{l}0.12^{* * *} \\
(0.02)\end{array}$ & $\begin{array}{l}0.19^{* * *} \\
(0.04)\end{array}$ & $\begin{array}{l}0.15^{*} \\
(0.08)\end{array}$ \\
\hline log(Market Tightness) & & $\begin{array}{c}0.14^{* * *} \\
(0.05)\end{array}$ & & & & \\
\hline Value Added Growth & $\begin{array}{c}1.11 \\
(0.76)\end{array}$ & $\begin{array}{l}0.51 \\
(0.52)\end{array}$ & $\begin{array}{c}0.16 \\
(0.72)\end{array}$ & $\begin{array}{l}2.00^{*} \\
(1.07)\end{array}$ & $\begin{array}{c}0.75 \\
(0.53)\end{array}$ & $\begin{array}{l}0.60 \\
(0.61)\end{array}$ \\
\hline $\log ($ Low Qualification) & & & & & $\begin{array}{l}0.46^{* *} \\
(0.23)\end{array}$ & \\
\hline $\log ($ Share Long-term U) & & & & & & $\begin{array}{c}0.23 \\
(0.16)\end{array}$ \\
\hline Constant & $\begin{array}{c}-0.79^{* * *} \\
(0.04)\end{array}$ & $\begin{array}{c}-0.58^{* * *} \\
(0.08)\end{array}$ & & & $\begin{array}{c}0.15 \\
(0.46)\end{array}$ & $\begin{array}{c}-0.56^{* * *} \\
(0.20)\end{array}$ \\
\hline Observations & 24 & 24 & 120 & 192 & 24 & 18 \\
\hline $\mathrm{R}^{2}$ & 0.37 & 0.55 & 0.14 & 0.13 & 0.62 & 0.36 \\
\hline Adjusted $R^{2}$ & 0.31 & 0.48 & 0.09 & 0.09 & 0.56 & 0.23 \\
\hline Residual Std. Error & $0.11(\mathrm{df}=21)$ & $0.09(\mathrm{df}=20)$ & & & $0.09(\mathrm{df}=20)$ & $0.13(\mathrm{df}=14)$ \\
\hline F Statistic & $6.07^{* * *}(\mathrm{df}=2 ; 21)$ & $8.18^{* * *}(d f=3 ; 20)$ & $8.87^{* * *}(\mathrm{df}=2 ; 113)$ & $14.16^{* * *}(\mathrm{df}=2 ; 182)$ & $10.94^{* * *}(\mathrm{df}=3 ; 20)$ & $2.66^{*}(\mathrm{df}=3 ; 14)$ \\
\hline
\end{tabular}

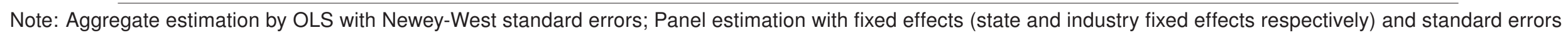

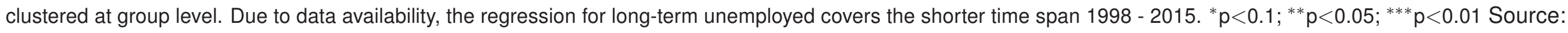




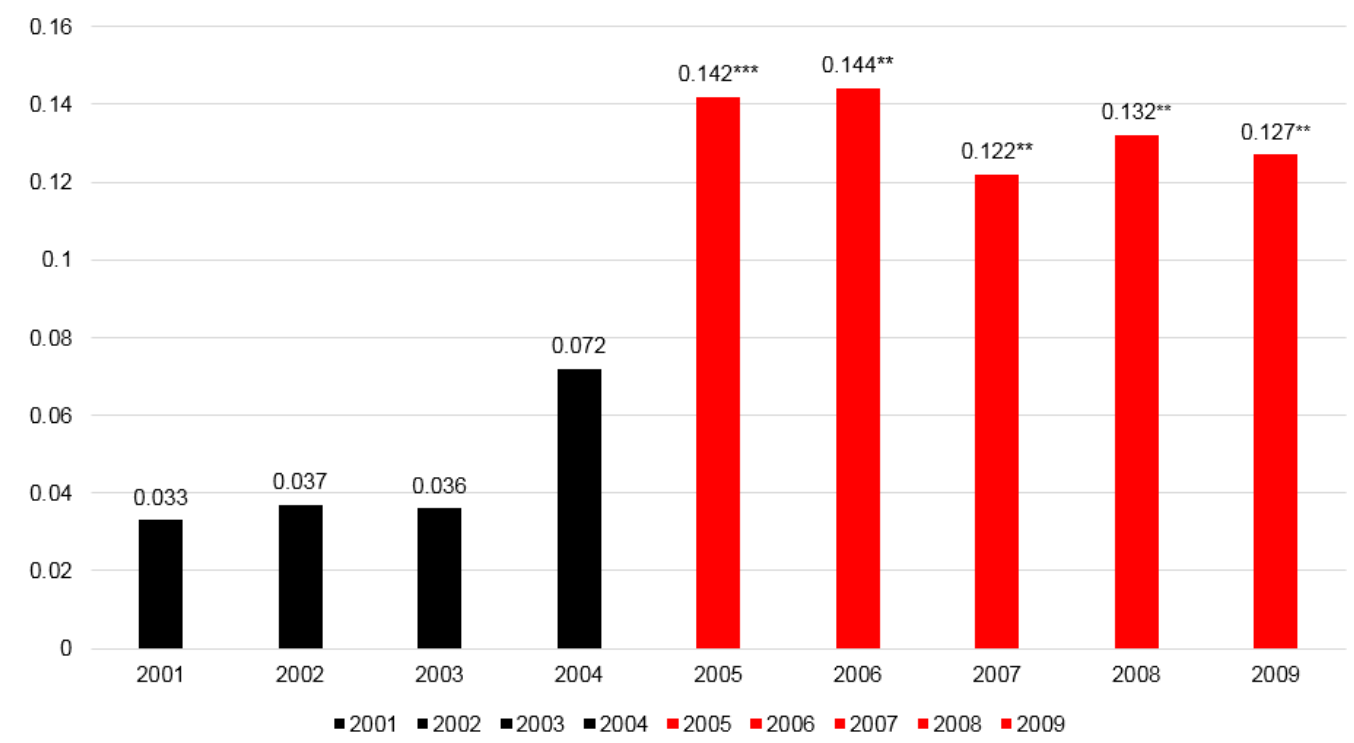

Note: The red bars denote significant dummy estimates at the 1 percent $\left({ }^{* \star *}\right)$ and 5 percent $\left(^{* \star}\right)$ significance level. Source: Own calculations.

Figure 6: Alternative shift-dummies starting in each respective year (controlling for value added growth).

Finally, although we cannot establish a causal relationship between Hartz IV and the partial effect on the selection rate in a microeconometric sense (due to the lack of the panel dimension in the data), our approach has two virtues: (i) we are the first to create (semi)aggregated time series that correspond directly to the partial effect in our model, (ii) we show that the selection rate has shifted upwards in an economically and statistically significant way from 2005 onwards. We believe that reverse causality is not an issue in our regressions because the Hartz IV reform was an exogenous event that was certainly not affected by the selection rate. The parliamentary discussions about the Hartz IV reform started in 2003. The Hartz IV law passed both chambers in 2004. To the extent that employers and employees anticipated the reform, our model predicts that the selection rate would already increase before the actual implementation. In this case, we would expect a significant placebo shift dummy for 2004, which we do not find (Figure 6). Even if anticipation effects played a role, our dummy estimate for 2005 would constitute a lower bound. Above, we have also briefly discussed that there may be indirect effects from market tightness on wages and thereby selection. However, controlling for market tightness leaves our results largely unaffected.

As further reassuring evidence, we can compare ourselves to Price (2018) who uses German administrative worker-level data to analyse the partial effect of Hartz IV. He estimates the causal microeconomtric effects of Hartz IV. We show below that our and Price s (2018) partial effects are of a similar order of magnitude despite a different data source and very different methodologies. Our partial effects are even more conservative. Finally, while the similarity of the partial effects of our and Price's (2018) approach is very reassuring, the benefit of our framework is that we provide additional and independent evidence and can make statements on the size of the equilibrium effect on top of the partial effect. 


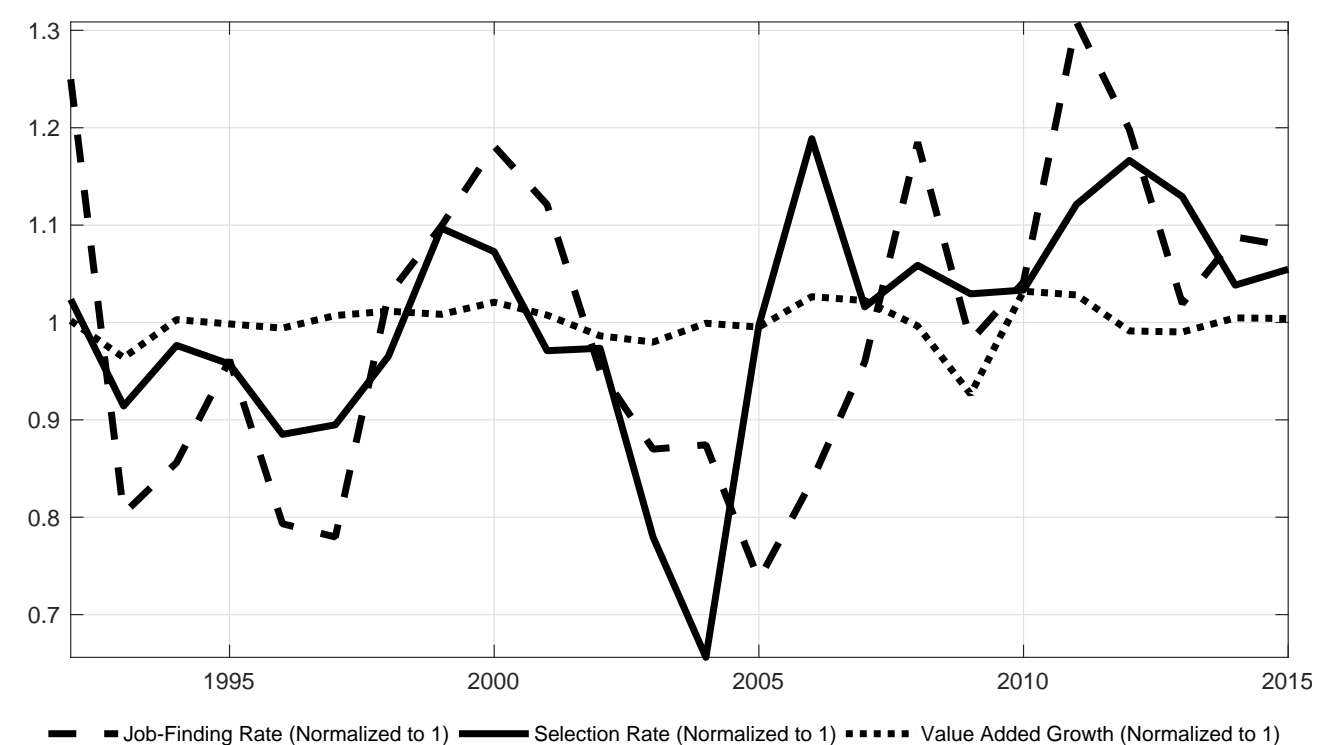

Figure 7: German labour market dynamics and value added growth (as gross rate), 19922015. Source: Own calculations based on data from the German Federal Statistical Office, the IAB Job Vacancy Survey and the IEB.

\subsection{Determining the Importance of Partial and Equilibrium Effect}

We target the estimated partial effect of Section 4.3 in our calibration. In different words, in our simulation exercise, we reduce the long-term unemployment benefits by the amount necessary to obtain a 13 percent increase of the aggregate selection rate in a partial equilibrium version of our model, i.e. keeping contact rates constant. ${ }^{32}$ This corresponds to the coefficient obtained from column (2) of Table 1 in which we control for both value added growth and tightness. ${ }^{33}$ Our approach distinguishes us from Krause/Uhlig (2012), Krebs/Scheffel (2013), and Launov/Wälde (2013) who all impose a certain decline of the replacement rate based on exogenous sources. Instead, we target an outcome variable of our model observable in the data.

Now, given an estimate for the partial effect, we need to determine the relative importance of partial and equilibrium effect. As explained in Section 4.2, we make use of two insights from our model: The relative importance of partial and equilibrium effects are the same for benefit and business cycle shocks and the elasticity of the job-finding rate with respect to market tightness is determined by the elasticity of the selection and contact rate with respect to market tightness:

$$
\frac{\partial \hat{p}_{t} / \partial \hat{b}_{t}}{\partial \hat{\eta}_{t} / \partial \hat{b}_{t}} \approx \frac{\partial \hat{p}_{t} / \partial \hat{\theta}_{t}}{\partial \hat{\eta}_{t} / \partial \hat{\theta}_{t}}
$$

\footnotetext{
32 We could also target the increase of the selection rate in the full equilibrium model. However, as we condition on tightness in the estimation, we do the same in our calibration. In addition, the feedback effect lowers the response of the selection rate. We therefore choose the more conservative strategy.

33 The coefficients in Table 1 show that our results would not differ much if we chose a different baseline specification.
} 
Table 2: Regression results for West Germany, 1992-2015.

\begin{tabular}{lcc}
\hline \hline & & Dependent variable: \\
\cline { 2 - 3 } & $\log ($ selection rate) & $\log ($ job-finding rate) \\
\hline $\log$ (Market Tightness) & $0.15^{* * *}$ & $0.31^{* * *}$ \\
& $(0.05)$ & $(0.07)$ \\
Hartz IV Dummy & $0.13^{* * *}$ & 0.02 \\
& $(0.04)$ & $(0.05)$ \\
Constant & & $-2.54^{* * *}$ \\
& $-0.56^{* * *}$ & $(0.07)$ \\
\hline Observations & $(0.09)$ & 24 \\
$\mathrm{R}^{2}$ & & 0.53 \\
Adjusted $\mathrm{R}^{2}$ & 24 & 0.49 \\
Residual Std. Error (df $=21)$ & 0.54 & 0.13 \\
F Statistic (df = 2; 21) & 0.50 & $12.05^{* * *}$ \\
\hline \hline
\end{tabular}

Note: Estimation by OLS with Newey-West standard errors; ${ }^{*} p<0.1 ;{ }^{* *} p<0.05 ;{ }^{* * *} p<0.01$. Source: Own calculations

$$
\frac{\partial j \hat{f} r_{t}}{\partial \hat{\theta}_{t}} \approx \frac{\partial \hat{p}_{t}}{\partial \hat{\theta}_{t}}+\frac{\partial \hat{\eta}_{t}}{\partial \hat{\theta}_{t}}
$$

Our newly constructed time series allows us to estimate both the elasticity of the job-finding rate and the elasticity of the selection rate with respect to market tightness. We run the following regressions:

$$
\begin{gathered}
\ln j f r_{t}=\varphi_{0}+\varphi_{1} \ln \theta_{t}+\varphi_{2} D_{t}^{\text {Hartz IV }}+\zeta_{t}, \\
\ln \eta_{t}=\beta_{0}+\beta_{1} \ln \theta_{t}+\beta_{2} D_{t}^{\text {Hartz } I V}+\nu_{t},
\end{gathered}
$$

Note that we also include a dummy for the Hartz IV reform in order to control for the structural shift in the unemployment series caused by the reform.

The estimated elasticities are equal to 0.31 for the job-finding rate and 0.15 for the selection rate (see Table 2). We are the first to estimate the elasticity of the selection rate from time series data and thereby to quantify the contribution of the selection margin for the behaviour of the job-finding rate over the business cycle. By targeting both estimated elasticities in a dynamic business cycle simulation of our model, we can uniquely determine the contact elasticity, in turn.

Two things are worth pointing out in this context. First, the estimated elasticity of the jobfinding rate with respect to market tightness is well in line with other matching function estimations for Germany such as Hertweck/Sigrist (2013) (based on data from the German Socio-Economic Panel) and Kohlbrecher/Merkl/Nordmeier (2016) (based on detailed administrative data). Second, in line with our model prediction, the elasticity of the selection rate with respect to market tightness is smaller than the elasticity of the job-finding 
rate ${ }^{34}$ Thus, the dynamics of the job-finding rate is both driven by contact and selection. To be more precise, about one half of the dynamics of the job-finding rate is driven by the selection rate and about one half is driven by the contact rate. The partial effect and the equilibrium effects are of roughly similar size. ${ }^{35}$

Although this subsection tackles the relative importance of the equilibrium relative to the partial effect, it may appear surprising that the Hartz IV shift dummy is statistically significant in the specification with the selection rate as dependent variable, but not in the specification with the job-finding rate (see Table 2). Note that this is related to the change in the registration requirements for unemployment in 2005 (as discussed before). Several hundred thousand additional workers were added to the pool of unemployed in 2005. This depresses the job-finding rate from 2005 onwards (defined as matches over unemployment) and thereby biases the estimated coefficient in Table 2 downwards. By contrast, the selection rate is not subject to this statistical break. In Appendix C.2, we correct for the structural break of the job-finding rate in two different ways. These corrections affect the estimated elasticity of the job-finding rate with respect to market tightness very little. However, under both corrections, we obtain a statistically significant coefficient on the Hartz IV dummy in the job-finding rate specification. Given that our correction approach is rough and the response of the job-finding rate in 2005 is not a target in our model, correcting for the structural break is not a concern for our calibration.

\section{Calibration}

We calibrate our model to West-German data. ${ }^{36}$ We choose a monthly frequency with a discount factor of $0.99^{\frac{1}{3}}$ and normalise aggregate productivity to 1 . Furthermore, we assume that firms and households have equal bargaining power (i.e. $\alpha=0.5$ ). The short-term unemployed in Germany receive unemployment benefits that amount to 60 percent or 67 percent of the last net wage, the long-term unemployed received 53 percent or 57 percent prior to the Hartz IV reform. As the unemployed may also enjoy some home production or utility from leisure, we choose the upper bound of the legal replacement rates for our calibration. We set the replacement rates to 67 and 57 percent of the steady state incumbent wage in our model. We set the monthly separation rate to 1.6 percent to target a steady state unemployment rate of 9 percent. This corresponds to the average unemployment rate in our sample prior to the reform. Likewise, we target the steady state market tightness to its pre-reform empirical average of 0.25 , which pins down the value of the vacancy posting costs.

The rest of the parameters are pinned down by six additional targets that we can measure in the data: The exit rates out of short-term and long-term unemployment, the aggregate

\footnotetext{
34 If the inverse was true, the contact rate would have to be countercyclical. This would stand in contradiction to standard contact functions.

${ }^{35}$ Kohlbrecher/Merkl/Nordmeier (2016) determine the relative importance of the two effects based on microeconomic administrative residual wage data. Their exercise yields similar results in this regard.

${ }^{36}$ We restrict our analysis to West Germany, as we do not want our regressions to be distorted by labour market transition effects in East Germany at the beginning and middle of the 1990s. Note, however, that we obtain a similar partial Hartz IV effect when we estimate the effects for Germany as a whole.
} 
selection rate, the relative contact rates of long-term versus short-term unemployed, as well as the elasticity of both the selection rate and the job-finding rate with respect to market tightness.

Table 3: Parameters and targets for calibration.

\begin{tabular}{lll}
\hline Parameter/Target & Value & Source \\
\hline Aggr. productivity & 1 & Normalisation \\
Discount factor & $0.99^{\frac{1}{3}}$ & Standard value \\
Short-term replacement rate & 0.67 & Legal replacement rate \\
Long-term replacement rate (pre-reform) & 0.57 & Legal replacement rate \\
Bargaining power & 0.5 & Standard value \\
Separation rate & 0.016 & Unemployment rate of 0.09 \\
Short-term job-finding rate & 0.16 & Klinger and Rothe (2012) \\
Long-term job-finding rate & 0.07 & Klinger and Rothe (2012) \\
Relative contact rate of long-term unemp. & 0.45 & PASS survey \\
Market tightness & 0.25 & IEB and Job Vacancy Survey \\
Selection rate & 0.46 & Job Vacancy Survey \\
$\partial \ln \eta / \partial \ln \theta$ & 0.15 & IEB and Job Vacancy Survey \\
$\partial \ln j f r / \partial \ln \theta$ & 0.31 & IEB and Job Vacancy Survey \\
\hline
\end{tabular}

Using the data provided by Klinger/Rothe (2012), the pre-reform exit rates out of unemployment are 16 and 6.5 percent for short-term and long-term unemployed. In our model, this could be driven by both lower contact rates and lower selection rates over time. How can we differentiate between the two? We observe the average pre-reform selection rate form the Job Vacancy Survey, which is 46 percent, and take that as given. Unfortunately, we cannot differentiate selection rates for long-term and short-term unemployed with our firm dataset. We therefore use information contained in the IAB PASS survey. ${ }^{37}$ In this survey, respondents are asked whether they have had a job interview during the last four weeks. We compute the contact rate as the share of respondents who answer this question affirmatively. It turns out that the contact rate for ALG II recipients (i.e. long-term unemployed) is 45 percent of the contact rate for ALG I recipients (i.e. short-term unemployed). We accordingly set the relative contact efficiency of the long-term unemployed to 45 percent. Together with the targeted aggregate selection rate and the exit rates for long- and short-term unemployed this pins down all the contact, selection, and job-finding rates in the economy. Note that while we assume that all short-term unemployed face the same contact, selection, and job-finding rate ${ }^{38}$ our calibration implies that the fixed training costs component increases every month with the duration of unemployment. ${ }^{39}$

We assume that idiosyncratic productivity follows a lognormal distribution. As shown by Kohlbrecher/Merkl/Nordmeier (2016), in a selection model the elasticity of the selection rate with respect to market tightness is determined by the shape of the idiosyncratic productivity distribution at the cutoff point. Given the distribution, the cutoff point is in turn determined

\footnotetext{
37 For a description of the IAB PASS survey, see Appendix B

${ }^{38}$ While we observe different job-finding rates per month of short-term unemployment duration in the data, we cannot compute the corresponding contact rates.

39 As the reservation wage falls with duration of unemployment, average training costs have to increase if we want to keep the steady state job-finding rates fixed.
} 
by the selection rate, which we have already targeted. We can therefore pin down the parameters of the distribution by targeting the elasticity of the selection rate with respect to market tightness, which is 0.15 in our data ${ }^{40}$ The elasticity of the contact rate with respect to market tightness (i.e. the weight on vacancies in the contact function) is finally set to target the overall elasticity of the job-finding rate with respect to market tightness, which is 0.31 in the data. The resulting weight on vacancies in the contact function is 0.14 . Thus, the selection mechanism accounts for about half of the elasticity of the job-finding rate with respect to market tightness in our model.

\section{The Effects of Hartz IV}

This section proceeds in three steps. First, we show the partial effects in our model. Although we target the aggregate partial effect in our estimation, we can make statements on the response of the selection rate for each unemployment duration group. Second, we switch on equilibrium effects and analyse how aggregate unemployment and vacancies changed due to Hartz IV. Third, we put our quantitative results in perspective to other papers on the German Hartz reforms.

\subsection{Partial Effects}

Our empirical estimation in Section 4.3 has shown that the reform resulted in a 13 percent increase of the selection rate (controlling for aggregate market tightness). We therefore target the same increase of the average selection rate in the quantitative model, while keeping equilibrium effects switched off (i.e. a constant contact rate).

For this purpose, we require a decline of unemployment benefits for long-term unemployed of 11 percent. Under collective bargaining the required drop is 23 percent (see Appendix C.1). For a given drop of workers' reservation wages initiated by the fall of the replacement rate, firms are willing to extend hiring by more when wages are bargained individually. The reason is that part of the increase in training costs for the marginal worker is directly offset by her wage. Conversely, if wages are bargained collectively, the increase in training costs for the marginal worker is only indirectly reflected in her wage, i.e. through its effect on average training costs. We therefore require a larger fall of the replacement rate to achieve the same response of the selection rate under collective bargaining. Nonetheless, both values are within the range used by Launov/Wälde (2013), Krause/Uhlig (2012), and Krebs/Scheffel (2013). Apart from the size of the replacement rate change, our results under collective bargaining are virtually unchanged (see Appendix C.1).

These results stress another important aspect of our evaluation strategy. By directly targeting the empirical increase of the selection rate (i.e. the partial effect), our results for the effects of the Hartz IV reform on the job-finding rate are robust to a number of modelling choices. This does not only apply to the wage bargaining regime. In a recent paper,

\footnotetext{
40 The resulting scale parameter of the distribution is 3.8. Note that we fix the location parameter of the distribution at 0 and instead allow the fixed training costs component to adjust. This allows us to vary the mean of the training costs for different groups while preserving the shape of the distribution.
} 
Hartung/Jung/Kuhn (2018) argue that separation rates declined sharply as a result of the Hartz IV reform which contributed to the decline of the unemployment rate. If separation rates indeed fell due to the reform, this would further boost the response of the selection rate in our model. Given that the empirical target for the increase of the selection rate is unchanged, we would require a lower drop of the replacement rate in this scenario. Overall, adding a separation channel to our model would of course further increase the effects on the unemployment rate, but leave the job-creation margin unaffected.

Figure 8 shows the impulse responses of the selection rate in reaction to this permanent decline of the replacement rate for long-term unemployed. The selection rate immediately
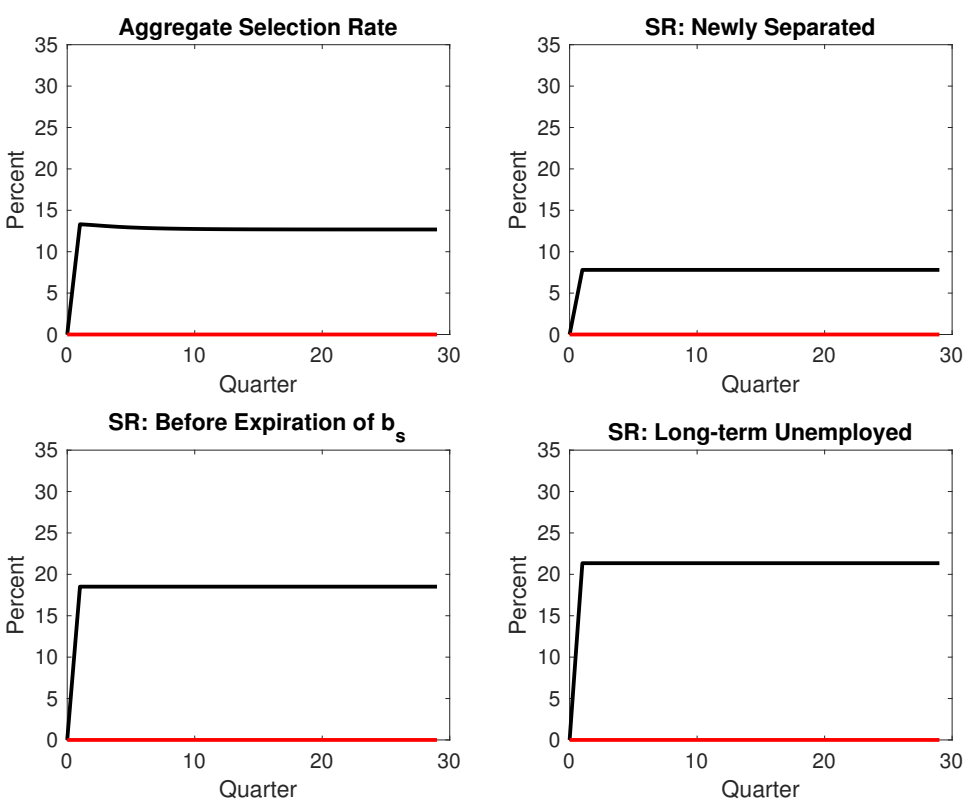

Figure 8: Selection rate (SR): impulse responses to a 11 percent decline in long-term unemployment benefits. Source: Calibrated model

increases on impact for all groups of searching workers due to a lower outside option. However, the effect is larger, the closer the unemployed get to the expiration of the more generous short-term benefits. For workers who have just been separated from a job (upper right panel in Figure 81, the reduction of long-term unemployment benefits affects their present value of unemployment by the least because they will only feel the reduction if they are not matched within the next twelve months. Still, their outside option falls, which increases the joint surplus of a match. The selection rate for workers who still have a full year of short-term benefits increases by around 8 percent. For workers who switch to the long-term benefit scheme in the next period, the reduction in long-term benefits has a larger effect on their outside option. Their selection rate increases by 19 percent. This is in line with Price (2018) who finds that unemployed workers' job-finding rates increase sharply before the expiration of benefits. Finally, the impact is largest for the long-term unemployed who are immediately affected by the reduction of long-term benefits. Their selection rate increases by 21 percent. ${ }^{41}$ Figure 9 shows the impact responses of the selection rate in

$\overline{41}$ While the individual selection rates all adjust on impact, the aggregate rate, which is a weighted average, 
response to a decline in long-term unemployment benefits for all duration groups of our model. The $x$-axis indicates the time remaining until short-term benefits expire. We see that the response increases gradually with the expiration of short-term benefits coming nearer and kinks at the expiration threshold.

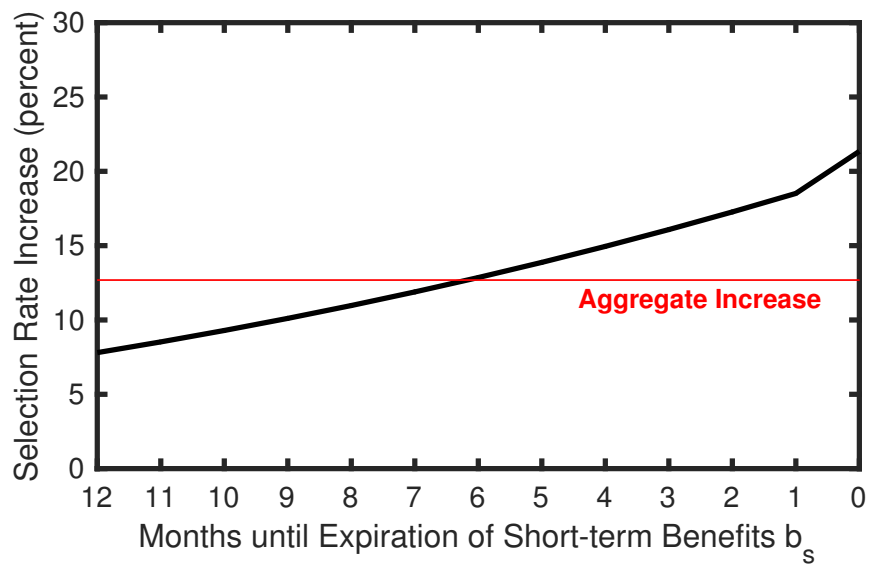

Figure 9: Impact responses of selection rate to a decline of long-term unemployment benefits by remaining months of short-term benefit entitlement. Source: Calibrated model

How do our results compare to other recent microeconometric studies of the Hartz IV reform? Price (2018) uses the German administrative data to estimate the causal effects of Hartz IV from the worker side. He finds that the probability of being reemployed within 12 months of beginning a claim increases by 4.7 percentage points. We find an increase of the reemployment hazard of 3.1 percentage points, which is smaller but close to Price's (2018) results. Furthermore, the magnitudes of the wage effects in our model are quite comparable. In our model, the average wage over the employment spell for a reemployed worker who exhausted short-term benefits falls by 2.6 percent due to Hartz IV. Price (2018) finds that those workers accept 4 to 8 percent lower wages on reemployment after the reform and conditional on jobless duration. ${ }^{42}$ The wage effect is much smaller if we average over all unemployment durations. In this case the average reemployment wage drops by only 1.1 percent. Note that the results in this subsection all rule out equilibrium effects, as we fixed the contact rate at its pre-reform level. In the full equilibrium model, average reemployment wages (again measured as average wages over the employment spell) drop by only 0.6 percent. As wage effects are crucial for the transmission of the benefit shock in our model, it is reassuring that these are well in line with empirical estimates. This is particularly important in light of the debate in the empirical literature as to whether benefits actually influence reemployment wages once controlling for unemployment duration. Schmieder/von Wachter/Bender (2016), for example, find for the pre-Hartz period in Germany that the effect of benefit duration on wages is at best very small. However, they study a different time period and identify their effects based on age related differences in the maximum duration of short-term benefits. In the pre-Hartz period, however, upon

slightly overshoots at the beginning. The reason is a composition effect. Initially, there are more long-term unemployed for whom the effect is largest. However, the difference between the initial response and the steady state response is small (around $1 \mathrm{pp}$ ).

42 We cannot make this distinction in our model as there is a one to one relationship between duration and benefit eligibility. 
exhaustion of short-term benefits, workers still received relatively generous long-term benefits. The Hartz IV reform, however, meant that entering long-term unemployment became a lot more painful which might explain why Price (2018) finds larger effects on wages for those workers close to the expiration of short-term benefits. Finally, it is important to stress that the similarity in results between our study and Price (2018) is quite remarkable, given that we derive our partial effects based on completely different methodologies and data sources: the administrative worker data (in the case of Price (2018)) and firm survey data (this study).

\subsection{Equilibrium Effects}

One of the key advantages of our approach relative to pure microeconometric estimations is that we can quantify the equilibrium effect. We now present results for the full model, i.e. we allow contact rates to adjust. Keep in mind that we have disciplined the relative magnitude of the equilibrium effect by our estimations in Section 4.4

As firms' expected surplus rises, they post more vacancies. More vacancies increase the market tightness and thereby increase the probability of workers to get in contact with a firm (through the contact function). This is illustrated in the lower left panel of Figure 10. The contact rate for unemployed workers rises by 10 percent on impact. ${ }^{43}$ The overall aggregate job-finding rate, which is the product of both the contact and the selection rates, increases by 22 percent on impact (lower right panel of Figure 10). Therefore, about half of the initial response of the job-finding rate is due to the equilibrium effect. Note that the response of the selection rate (12 percent increase on impact, 11 percent higher in the new steady state) is a bit smaller in the full model compared to the model with the equilibrium effect switched off. The reason is a small negative feedback effect from increased contact rates on the wage level and hence the selection rate. Overall, the unemployment rate falls by 24 percent. This corresponds to a decrease of the unemployment rate by 2.2 percentage points in our calibration.

When the economy adjusts to a new steady state, the composition of the pool of unemployed changes. This can be seen in the adjustment dynamics of the contact and jobfinding rate, which increase quite sluggishly. ${ }^{44}$ The aggregate contact and job-finding rates are a weighted average for all duration groups. Due to the reform, the duration of unemployment is shortened. The share of the searching workers with long unemployment duration declines over time ${ }^{45}$ When we control for the composition effect: ${ }^{46}$ the unemployment rate falls by 19 percentage or 1.7 percentage points (instead of 2.2 percentage points). The increase of the selection rate (partial effect) and the contact rate (equilibrium effect) each account for roughly half of this decline.

\footnotetext{
$\overline{43}$ As all workers search on the same labour market, the relative response of the contact rate to the reform is the same for short and long-term unemployed.

44 The new steady state is only reached after 7 years.

45 In principle, the composition effect could also be driven by selection. However, in our calibration, most of the differences in job-finding rates between long- and short-term unemployed are accounted for by lower contact efficiencies, which was guided by the PASS survey.

${ }^{46}$ We assume counterfactually that the shares of each unemployment duration group stay constant.
} 

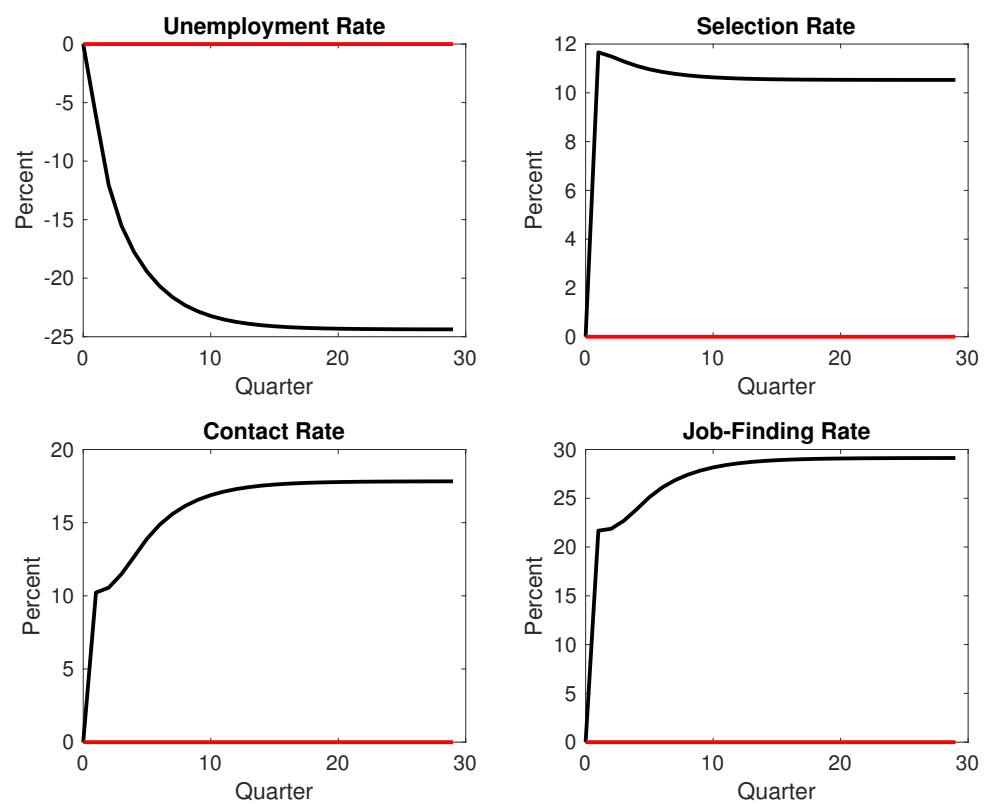

Figure 10: Impulse responses to a decline in long-term unemployment benefits. Source: Calibrated model

In the long run, the job-finding rate in our simulated model increases by almost 30 percent. At first sight, it seems surprising given that the job-finding rate before relative to after the Hartz IV reform appears to increase by less in the aggregate data (see Figure 5). Several comments are in order. First, once we correct for the structural break in the unemployment series (see Appendix D.2), we obtain a descriptive increase of the job-finding rate of 15-17 percent. However, the comparison is quite sensitive to the chosen time period. If we choose the same time period as Hartung/Jung/Kuhn (2018), we obtain an increase of around 20 percent. If we compare the two recessions 2005 and 2009, we obtain an increase of around 30 percent. Second, it has to be emphasised that many workers may have left registered unemployment after 2005 (as they were not eligible for long-term benefits due to Hartz IV any more) before reentering employment. This is a caveat of the German unemployment definition, which is based on registration instead of active search. These transitions out of non-registration are not captured by the empirical job-finding rate but are included in our model response. Recent evidence on labour market flows between employment, nonregistration and registered unemployment by Carrillo-Tudela/Launov/Robin (2018) suggest that this was indeed an important adjustment channel.

Finally, it is interesting to study the trajectory of the Beveridge curve in the data and in the model. Figure 11 shows the simulated Beveridge curve in response to the decline of the replacement rate for long-term unemployed workers in our model. Vacancies increase, overshoot and end up at a level above the initial steady state. Unemployment sequentially declines to a lower long-run level. We contrast our simulation results with the actual movement of the Beveridge curve from the first quarter of 2005 to the fourth quarter of 2007 (Figure 12). Note that the increase in unemployment due to the change in requirements to register as unemployed can be seen visually in this figure. Similar to the simulation, 
vacancies increase, overshoot somewhat and end up at a higher level. ${ }^{47}$ Unemployment sequentially declines to a permanently lower level in the data. The movements are not only qualitatively comparable, but the quantitative reactions (as percent deviations) are also similar.

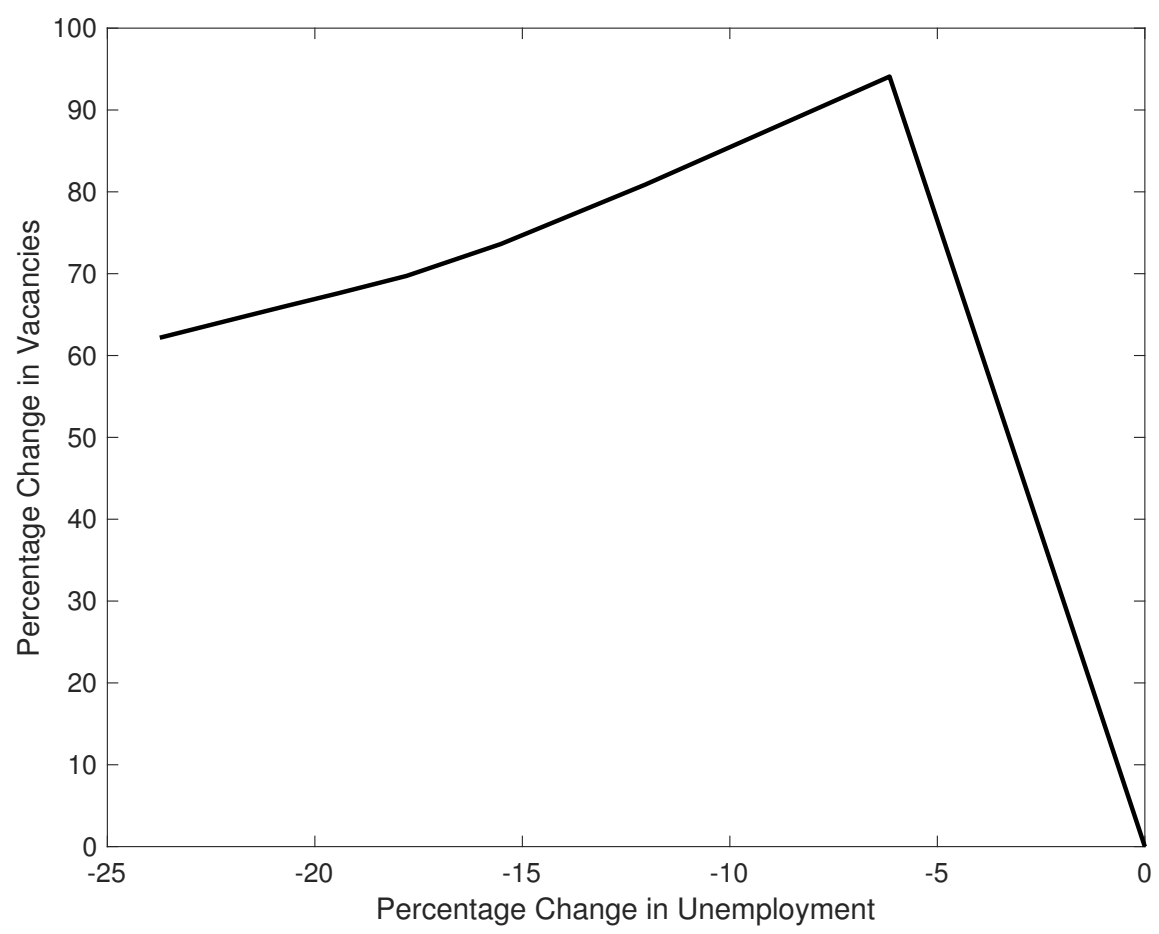

Figure 11: Beveridge curve generated by the model during first three years after the shock.

While the comparison of our simulation and the data is purely descriptive, given the similarities between the two, the exercise provides suggestive evidence for the importance of the Hartz IV reform for German labour market dynamics in the years after the reform. Overall, our work points to an important role of the reform of the benefit system for the decline of German unemployment. Other reforms (such as Hartz III) may also have contributed (e.g. Launov/Wälde, 2016). However, our methodology does not allow us to quantify these contributions.

\subsection{Broader Perspective}

How do our results compare to recent empirical studies on labour market stocks and flows around the time of the Hartz reforms? In recent papers, Carrillo-Tudela/Launov/Robin (2018) and Rothe/Wälde (2017) document that relatively few unemployed workers directly transitioned to regular (full-time) employment after Hartz IV. Indeed, Carrillo-Tudela/Launov/Robin (2018) show that flows into non-participation account for a large part of the outflows from unemployment in the aftermath of the Hartz IV reform but that labour force participation

\footnotetext{
47 The overshooting behaviour takes place later in the data and is somewhat less pronounced. Vacancies are a purely forward-looking variable in our model, while there may by reasons why they are more persistent in the data.
} 


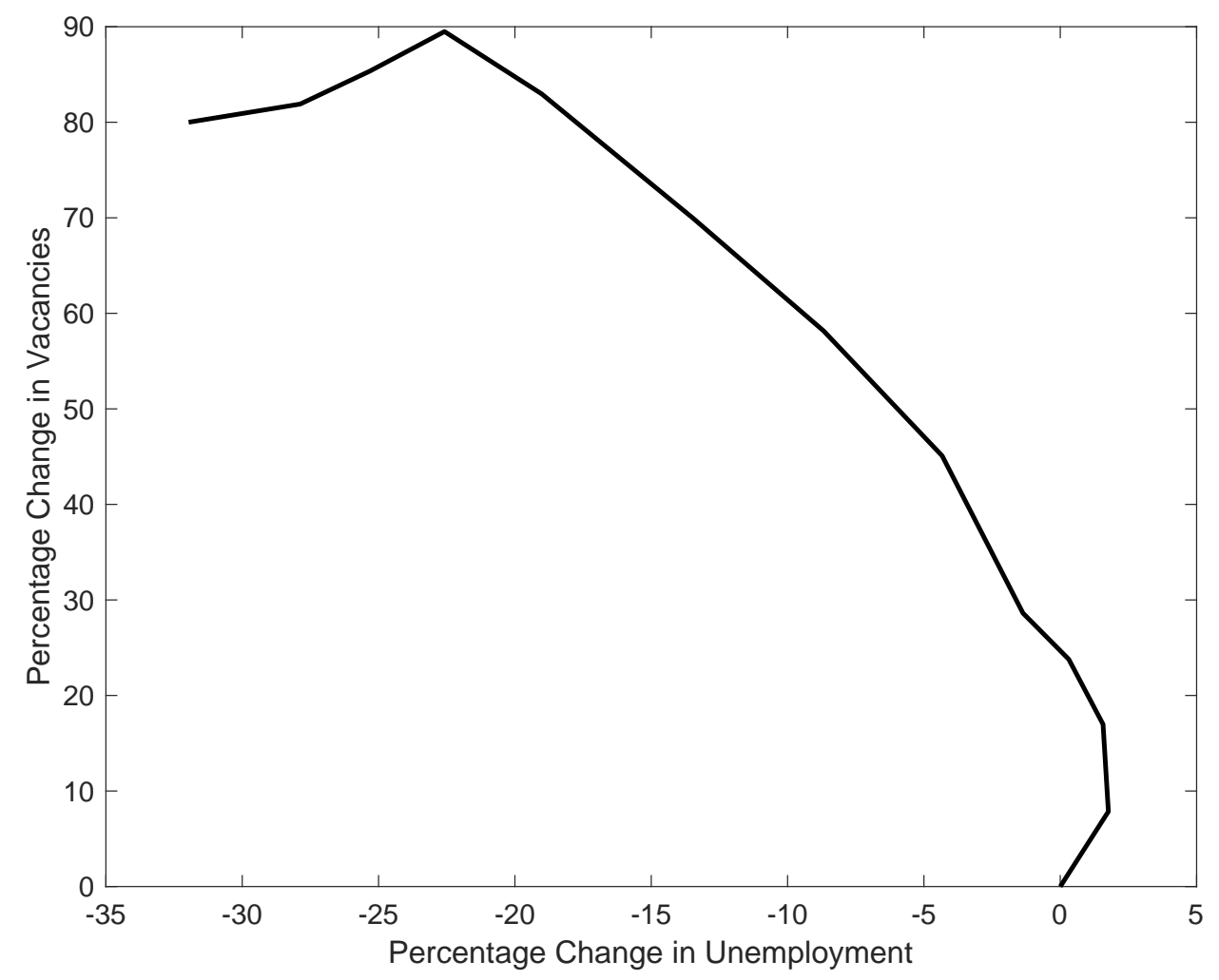

Figure 12: West German Beveridge curve from 2005-2007. Source: Own calculations based on data from the German Federal Labour Office.

actually increased. Apparently, the reform induced many unemployed to deregister with the Federal Employment Office, but then - out of non-participation - to take up jobs often in the form of part-time employment ${ }^{48}$ or mini-jobs. The latter then often served as stepping stones into contributing employment. Besides the known measurement issues with the unemployment rate in 2005 , these dynamics provide an additional argument why focussing on direct unemployment to employment transitions when assessing the Hartz IV reform would only show part of the picture.

Interestingly, these results contrast with the findings by Price (2018). He documents that the net-employment effects from his causal identification - which are comparable in magnitude to our partial effects - are driven by full-time employment. Still, against the background Carrillo-Tudela/Launov/Robin's (2018) and Rothe/Wälde's (2017) work, it may be the case that labour market transitions took place in a more complex and sluggish way than in our simulated model (e.g. via non-participation and irregular types of unemployment, which served as stepping stones). To the extent that stepping stones played an important role, our model overestimates the speed at which the equilibrium effect generates full-time jobs. To our knowledge, there exists no macroeconomic labour market framework which allows modelling stepping stone effects. Finally, understanding better the dynamics of participation decisions and their interaction with the benefit reform would certainly be desirable. However, besides the usual challenges of modelling participation decisions in quantitative models, the work by Carrillo-Tudela/Launov/Robin (2018) shows that the German case is

\footnotetext{
48 The rise in part-time employment around the time of the Hartz reforms is also documented in a recent paper by Burda/Seele 12016।.
} 
even more challenging as incentives to be registered as unemployed might be completely unrelated to search behaviour. Against this background, we have proposed a novel approach how to measure the partial effect of Hartz IV with a data source (IAB Job Vacancy Survey) that is completely unrelated to the definition of registered unemployment. Our new selection measure is robust to changed definitions of labour market states (related to unemployment registration) and resulting spurious labour market flows.

\section{Conclusion}

This paper proposes a novel approach how to evaluate the reform of the German unemployment benefits system in 2005. For this purpose, we construct a measure of labour selection over the business cycle. In contrast to existing literature, our strategy does not hinge on an external source for the quantitative decline of the replacement rate for longterm unemployed, for which the literature provides a wide range of estimates. Instead, we provide direct empirical evidence on firms' hiring behaviour from the IAB Job Vacancy Survey and show that their selection rates increased following the Hartz IV reform. In addition, we estimate the relative importance of partial and equilibrium effects over the business cycle and impose it on our model. Our simulation shows that the reform had important equilibrium effects. Our simulated model can match important facts, such as the trajectory of the Beveridge curve after the reform and the larger increase of the job-finding rate for unemployed with longer unemployment durations. Overall, our results show that 2.2 percentage points of the decline in unemployment since 2005 can be attributed to the Hartz IV reforms. It was thus a major driver of the decline of unemployment in Germany. 


\section{A Appendix: Details on the Hartz Reforms}

In response to rising unemployment in the early 2000s, the Hartz commission developed recommendations for the German labour market. These proposals were implemented gradually between 2003 (Hartz I and Hartz II) and 2005 (Hartz IV). According to Jacobi/Kluve (2006), the Hartz reforms had three main goals: (1) increasing the effectiveness and efficiency of labour market services, (2) activating the unemployed and (3) boosting labour demand by deregulating labour markets. Under the concept of "demanding and supporting" (Fordern und Fördern), these four reforms radically restructured the German labour market:

Hartz I (in action since 01/01/2003): This reform facilitated the employment of temporary workers. Additionally, vouchers for on-the-job training were introduced.

Hartz II (in action since 01/01/2003): Introduction of new types of marginal employment with low income such as Minijobs (up to 450 euros per month, exempted from the income tax) and Midijobs (income up to 850 euros per month, reduced social security contributions). Furthermore subsidies for business start ups of unemployed were introduced.

Hartz III (in action since 01/01/2004): The core element of Hartz III was the restructuring of the Federal Employment Agency. The Federal Employment Agency was divided into a headquarter, regional directorates and local job center. Those local job center are now managed via a target agreement. Since Hartz III, all claims of an unemployed person are processed by the same case worker (support from a single source) and an upper limit on the number of cases handled was introduced. Furthermore, a special focus was put on long-term unemployed and unemployed who are older than fifty years. In addition, market elements for private placement services and providers of training measures were introduced.

Hartz IV (in action since 01/01/2005): The last step was the most widely discussed reform since it caused a substantial cut in long-term unemployment benefits for several groups. Prior to the reform, unemployed workers who had exhausted their short-term unemployment benefits received unemployment assistance (Arbeitslosenhilfe) which amounted to 53 percent of previous net earnings (57 percent with children). In addition, unemployed workers not eligible for unemployment assistance (Arbeitslosenhilfe) received means-tested social assistance. Both forms of long-term unemployment benefits were abolished in 2005 and replaced by the purely means-tested Arbeitslosengeld (ALG) II (commonly called "Hartz IV"). This constituted a severe cut in long-term unemployment benefits for most former recipients of Arbeitslosenhilfe. Eligibility for ALG II depends on savings and the partner's income. In addition, a sanctioning system was introduced which allowed cuts in the fixed unemployment benefits if the unemployed person breaks an agreement with the Public Employment Agency (e.g. in terms of writing applications, reachability, responsible economic behaviour). In addition, the Hartz IV law also includes a reduction of the maximum entitlement duration of short-term unemployment benefits for workers older than 45 years by 6 to 14 months. This reform step became effective on February 1, 2006. For a more detailed description of the Hartz reforms, see Jacobi/Kluve (2006) or Launov/Wälde (2016). 


\section{B Appendix: Data}

We use West German annual data on the number of suitable applicants for the most recent hire in the last 12 months and the number of total vacancies of the IAB Job Vacancy Survey. Information on the IAB Job Vacancy Survey can be found in Moczall et al. (2015). Note that since the IAB Job Vacancy survey corresponds to the third quarter of a year, we use third quarter data in our estimations except for the value added measure. Regarding value added growth, we are restricted to use annual data as disaggregated national accounts data is only available at an annual frequency. The value added measure for West Germany is constructed by aggregating value added at state level and taking growth rates. In addition, data on unemployment and transitions from unemployment into employment (matches) were taken from register data of the federal labour office, the "Integrated Labour Market Biographies (IEB)" (vom Berge/Burghardt/Trenkle, 2013). ${ }^{49}$ We define the job-finding rate as matches over unemployment, where matches are transitions from unemployment into employment. Furthermore, a person is counted as unemployed if he or she does not have a job which is subject to the payment of social security contributions, is registered to be actively looking for a job or receives unemployment benefits.

Data for calculating the contact rate for short-term and long-term unemployed stems from the IAB PASS Survey. Furthermore, we take values on the job-finding rates for ALG I (shortterm unemployed) and ALG II recipients (long-term unemployed) from (Klinger/Rothe, 2012). They calculated these job-finding rates based on German administrative data. We use the average job-finding rate by duration of unemployment for the time span 1998-2004. ${ }^{50}$

\section{B.1 Appendix: Details on the IAB Job Vacancy Survey}

The Job Vacancy Survey was first carried out in 1989 in West Germany and was extended to East Germany in 1992. Note that due to the small number of East German establishments in the early 1990s in the sample and due to the different behaviour of labour market turnover rates (see Fuchs et al., 2018), we restrict our sample to West Germany. The survey is conducted via a written questionnaire every fourth quarter of the year. Yearly, a stratified random sample of establishments is drawn according to industries, regions as well as size classes. The number of establishments participating ranges from 4,000 in the first years to about 14,000 in the recent years. The data set includes weights to extrapolate the data for the whole economy. Weights for the most recent case of hiring ensure representativeness for all hires.

As the number of suitable applicants for Germany is available from 1992 onwards, we restrict our sample range from 1992 to 2015 . Since the aggregate sample range is quite short to conduct time series analysis, we additionally calculate the time series at the federal state and industry level. We aggregate the inverse of the number of suitable applicants by taking mean values. Following Klinger/Rothe (2012: p.17), we add the city state Bremen to the neighbouring state Lower Saxony to avoid spatial correlation. The Job Vacancy

\footnotetext{
49 Status quo of the data as of January 2016 .

50 This corresponds to the available pre-Hartz period.
} 
Survey contains too few observations for small federal states in order to be representative.

Therefore, we restrict our sample to federal states with at least 6 million inhabitants. ${ }^{51}$

\section{B.2 Appendix: Details on the IAB PASS Survey}

Furthermore, we use data of the IAB Panel Study Labour Market and Social Security (PASS) $^{52}$ to calculate the relative contact rates of long- and short-term unemployed workers. This annual Panel Survey was first carried out in 2007 and consists currently of ten waves. Each wave consists of approximately 10,000 households. Its focus lies on the circumstances and characteristics of recipients of Unemployment Benefit II (ALG II). Interview units are both households as well as individuals (15,000 each year). The Panel consists of two equally large subsamples, (a) recipients of unemployment benefits II (ALG II) and (b) a sample of the German population in which low-income households are overrepresented. ${ }^{53}$ In addition, the PASS survey includes several questions on the job search behaviour of unemployed workers. These questions regard job search channels, the number of applications as well as the number of job search interviews attended. We measure the contact rate in our model by calculating the share of unemployed workers who attended at least one job interview in the past four weeks. Furthermore, we split unemployed workers by short-term unemployed (ALG I recipients) and long-term unemployed (ALG II recipients). The number of unemployed workers in our sample is 1,806 for ALG I recipients and 23,103 for ALG II recipients. For a detailed description of the IAB PASS survey, see Trappmann et al. (2013).

\section{Appendix: Model Robustness}

\section{C.1 Collective Bargaining}

In the main part of the paper we assume that all wages are determined by individual Nash bargaining. However, a significant share of German wages are still set under collective bargaining arrangements. In 2010, 53 percent of all West German employees in the private sector were covered by collective bargaining (see e.g. Hirsch et al., 2014). We therefore present results for the polar opposite case, i.e. wages are bargained collectively. We assume that all workers within a duration group earn the same wage but still allow for differences between groups. We assume that the union represents the average worker that is hired in every group. The union wage is then again determined by Nash bargaining. We apply the exact same calibration strategy as in the main part of the paper (i.e. we keep the same targets). The only major difference between the collective and the individual Nash bargaining case is that the reduction of the replacement rate that is required for the targeted increase of the selection rate is higher under collective bargaining. More

\footnotetext{
51 As of December 2014. Hence, we include Baden-Wuerttemberg, Bavaria, North-Rhine Westphalia, Lower Saxony plus Bremen and Hessen.

52 Data access was provided via a Scientific Use File supplied by the Research Data Centre (FDZ) of the German Federal Employment Agency (BA) at the Institute for Employment Research (IAB), project no. 101752.

${ }^{53}$ For details, see http://www.iab.de/en/befragungen/iab-haushaltspanel-pass.aspx
} 
precisely, we require a 23 percent drop of long-term unemployment benefits to achieve a 13 percent increase of the selection rate in partial equilibrium (i.e. keeping the contact rate fixed). While this is more than double the amount required under individual Nash bargaining, it is similar to the reduction used by Krebs/Scheffel (2013) and Krause/Uhlig (2012) (for low-skilled workers). Figure C.1 shows that otherwise the model reaction is virtually unchanged.
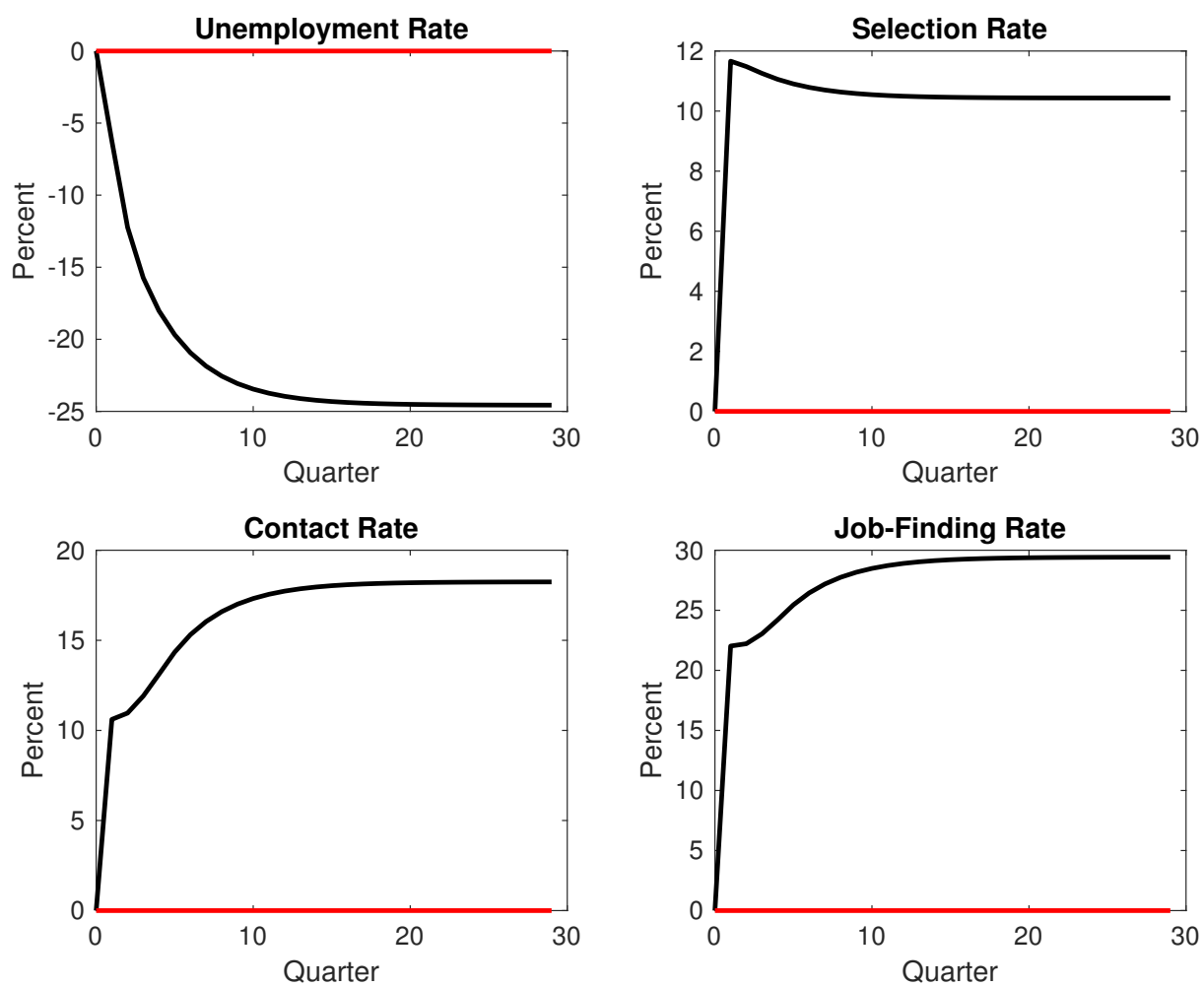

Figure C.1: Impulse responses to a 23 percent drop of long-term unemployment benefits under collective bargaining. Source: Calibrated model

\section{C.2 Matching Efficiency Shock}

Figure C.2 shows the response of the selection rate to a positive shock to the matching efficiency. A one percent increase of matching efficiency leads to a drop of the selection rate of around 0.1 percent. Thus, the effect is extremely small and - if any - would bias our results downward. 


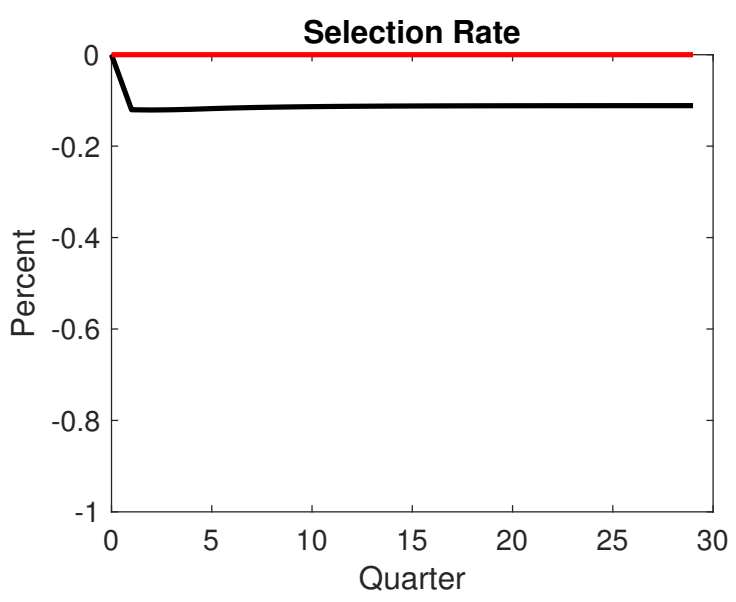

Figure C.2: Response of the selection rate to a 1 percent positive shock to the matching efficiency. Source: Calibrated model

\section{Appendix: Robustness of Empirical Strategy}

\section{D.1 Robustness of Partial Effect Estimations}

Table D.1 illustrates partial effect estimations of the selection rate increase after the Hartz IV reform conditional on market tightness as business cycle indicator (instead of value added growth).

\section{D.2 Correction of Unemployment Series}

As part of the transition from the old system of unemployment and social assistance to the new system of "Arbeitslosengeld II" ("Hartz IV"), the number of registered unemployed rose significantly in the first quarter of 2005. This increase has two reasons: First, former social assistance ("Sozialhilfe") recipients able to work were counted as unemployed (which was not the case prior to the reform). Second, family members of unemployment benefit recipients also had to register as unemployed under certain conditions (see Statistik der Bundesagentur für Arbeit, 2005). According to the Federal Employment Agency, the number of unemployed rose by 380.000 recipients (entire Germany) due to the new requirements to register as unemployed until March 2005 (Statistik der Bundesagentur für Arbeit, 2005: p. 10). Low-skilled workers and women were overrepresented among the newly registered workers. Given that unemployment increased for purely statistical reasons in 2005, this reduces the job-finding rate (which is defined as matches divided by unemployment) and it reduces the market tightness (which is defined as vacancies divided by unemployment). 
Table D.1: Estimates of the partial effect, results for West Germany, 1992-2015.

\begin{tabular}{|c|c|c|c|c|c|}
\hline & \multicolumn{5}{|c|}{ Dependent variable: } \\
\hline & \multicolumn{5}{|c|}{$\log ($ selection rate) } \\
\hline & OLS & \multicolumn{2}{|c|}{$\begin{array}{c}\text { Fixed effects panel } \\
\text { linear }\end{array}$} & \multicolumn{2}{|c|}{ OLS } \\
\hline & $\begin{array}{l}\text { Aggregate West Germany } \\
\text { (1) }\end{array}$ & $\begin{array}{l}\text { State Level } \\
\text { (2) }\end{array}$ & $\begin{array}{l}\text { Industry Level } \\
\text { (3) }\end{array}$ & $\begin{array}{l}\text { Aggr.: Low Qualification } \\
\qquad(4)\end{array}$ & $\begin{array}{c}\text { Aggr.: Long-term } U \\
(5)\end{array}$ \\
\hline Hartz IV Dummy & $\begin{array}{c}0.13^{* * *} \\
(0.04)\end{array}$ & $\begin{array}{c}0.10^{* * *} \\
(0.03)\end{array}$ & $\begin{array}{c}0.12^{* * *} \\
(0.03)\end{array}$ & $\begin{array}{c}0.17^{* * *} \\
(0.04)\end{array}$ & $\begin{array}{l}0.14^{* *} \\
(0.06)\end{array}$ \\
\hline log(market tightness) & $\begin{array}{l}0.15^{* * *} \\
(0.05)\end{array}$ & $\begin{array}{l}0.10^{* * *} \\
(0.01)\end{array}$ & $\begin{array}{l}0.08^{* * *} \\
(0.02)\end{array}$ & $\begin{array}{l}0.11^{* * *} \\
(0.04)\end{array}$ & $\begin{array}{c}0.14^{* * *} \\
(0.05)\end{array}$ \\
\hline log(low_qualification) & & & & $\begin{array}{l}0.39 * * \\
(0.17)\end{array}$ & \\
\hline log(share_long-term u) & & & & & $\begin{array}{l}0.18^{* *} \\
(0.07)\end{array}$ \\
\hline Constant & $\begin{array}{c}-0.56^{* * *} \\
(0.09)\end{array}$ & & & $\begin{array}{l}0.18 \\
(0.37)\end{array}$ & $\begin{array}{c}-0.41^{* * *} \\
(0.12)\end{array}$ \\
\hline Observations & 24 & 120 & 192 & 24 & 18 \\
\hline $\mathrm{R}^{2}$ & 0.54 & 0.22 & 0.18 & 0.72 & 0.53 \\
\hline Adjusted $\mathrm{R}^{2}$ & 0.50 & 0.18 & 0.14 & 0.67 & 0.43 \\
\hline Residual Std. Error & $0.09(\mathrm{df}=21)$ & & & $0.07(\mathrm{df}=20)$ & $0.11(\mathrm{df}=14)$ \\
\hline F Statistic & $12.50^{* * *}(\mathrm{df}=2 ; 21)$ & $16.25^{* * *}(\mathrm{df}=2 ; 113)$ & $20.57^{* * *}(\mathrm{df}=2 ; 182)$ & $16.83^{* * *}(\mathrm{df}=3 ; 20)$ & $5.32^{* *}(\mathrm{df}=3 ; 14)$ \\
\hline
\end{tabular}

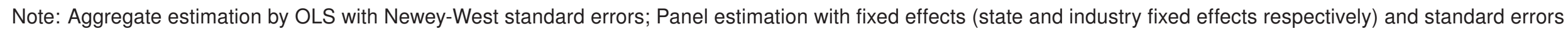

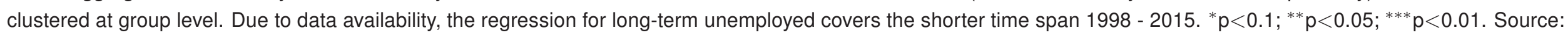
Own calculation 
In order to clear the break in the unemployment series, we apply two methodologies and compare the results. Our first approach is purely statistical. We estimate the growth rate of (seasonally) adjusted unemployment from the fourth quarter 2004 to the first quarter 2005. We correct the aggregate unemployment time series by the corresponding level difference. The second approach uses the number of additional unemployed published by the Federal Employment Agency. We weight the number of the additional unemployed for Germany by the share of unemployed in West Germany in the year 2005 (66.8 percent). This results in an overall number of approximately 254.000 unemployed which we deduct from 2005 onwards. Figure D.3 llustriates the original unemployment series (solid line, data based on the IAB Integrated Employment Biographies), the corrected series using the dummy approach (dashed line) and the corrected series using the number of the Federal Emplcy'ment agency (dotted line). The two correction methodologies deliver very similar series.

As a next step, we repeat our empirical estimations on the aggregate level for West Germany. Table D.2 shows that once controlling for the break in the unemployment series (as denominator for the job-finding rate and market tightness), the dummy for the Hartz IV reform becomes significant. ${ }^{54}$ In different words, we identify the structural break of unemployment as the underlying reason why the Hartz IV dummy is statistically significant for the selection rate in the main part, while it is not statistically significant for the job-finding rate. Correcting for the break yields a more coherent picture.

It is also noteworthy that the estimated elasticities of the selection rate with respect to market tightness in Table D.3 are identical to our baseline estimation (see Table 2). The estimated elasticity of the job-finding rate with respect to market tightness is slightly smaller (0.27 vs. 0.3).

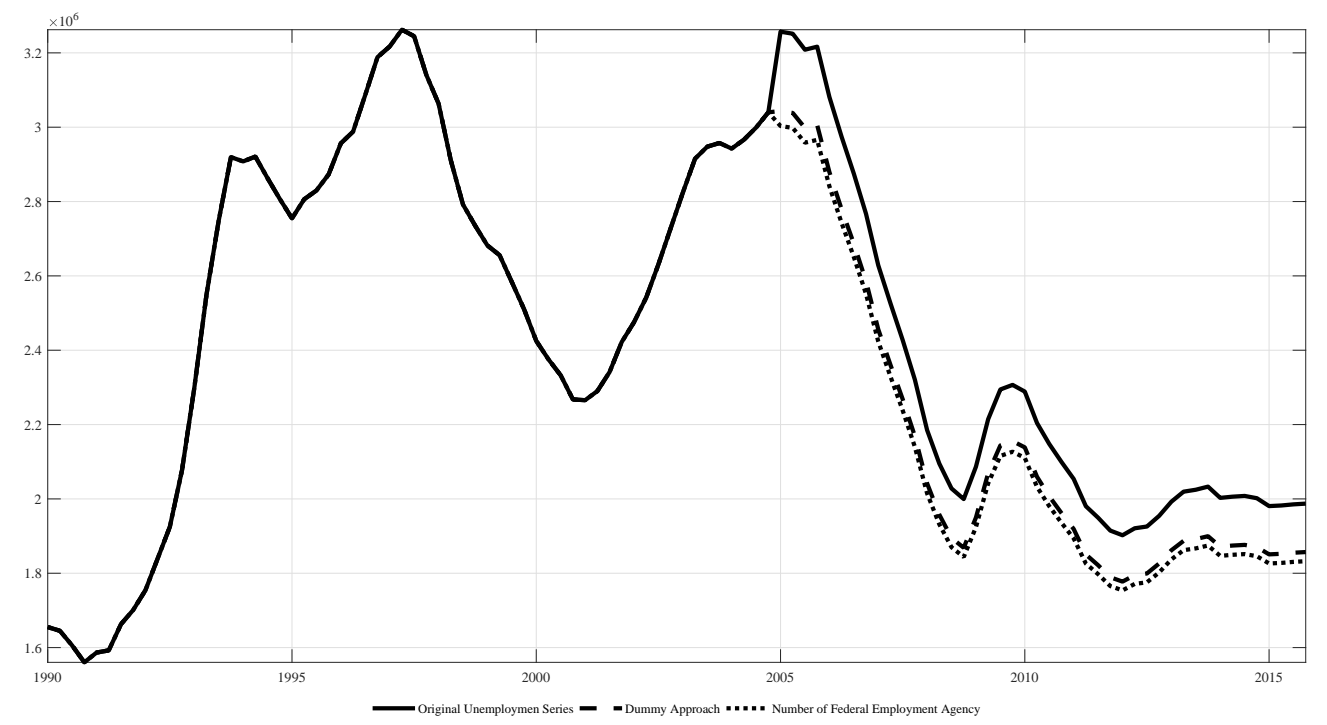

Figure D.3: Clearing for the break in the unemployment series, 1990Q1-2015Q4. Source: Own calculation based on data from the Federal Labour Office

\footnotetext{
$\overline{54}$ Note that we show the regression with the selection rate and value added growth again for completeness. However, this estimation is not affected by break correction.
} 
Table D.2: Correction method 1: Clearing the break in the unemployment series, 92-15

\begin{tabular}{|c|c|c|c|c|}
\hline & \multicolumn{2}{|c|}{ Dummy Approach } & \multicolumn{2}{|c|}{ Number of Federal Employment Agency } \\
\hline & $\log ($ selection rate) & $\log ($ job-finding rate) & $\log ($ selection rate) & $\log ($ job-finding rate) \\
\hline & (1) & (2) & (3) & (4) \\
\hline Hartz IV Dummy & $\begin{array}{c}0.14^{* * *} \\
(0.03)\end{array}$ & $\begin{array}{l}0.13^{*} \\
(0.07)\end{array}$ & $\begin{array}{c}0.14^{* * *} \\
(0.03)\end{array}$ & $\begin{array}{l}0.15^{* *} \\
(0.07)\end{array}$ \\
\hline Value Added Growth & $\begin{array}{c}1.11 \\
(0.76)\end{array}$ & $\begin{array}{l}1.46^{*} \\
(0.89)\end{array}$ & $\begin{array}{c}1.11 \\
(0.76)\end{array}$ & $\begin{array}{l}1.46^{*} \\
(0.89)\end{array}$ \\
\hline Constant & $\begin{array}{c}-0.79^{* * *} \\
(0.04)\end{array}$ & $\begin{array}{c}-3.02^{* * *} \\
(0.04)\end{array}$ & $\begin{array}{c}-0.79^{* * *} \\
(0.04)\end{array}$ & $\begin{array}{c}-3.02^{* * *} \\
(0.04)\end{array}$ \\
\hline Observations & 24 & 24 & 24 & 24 \\
\hline $\mathrm{R}^{2}$ & 0.37 & 0.28 & 0.37 & 0.31 \\
\hline Adjusted $\mathrm{R}^{2}$ & 0.31 & 0.21 & 0.31 & 0.24 \\
\hline Residual Std. Error $(\mathrm{df}=21)$ & 0.11 & 0.13 & 0.11 & 0.13 \\
\hline F Statistic $(\mathrm{df}=2 ; 21)$ & $6.07^{* * *}$ & $4.05^{* *}$ & $6.07^{* * *}$ & $4.72^{* *}$ \\
\hline
\end{tabular}

Note: Aggregate estimation by OLS with Newey-West standard errors; ${ }^{*} p<0.1 ;{ }^{* *} p<0.05$;

${ }^{* * *} \mathrm{p}<0.01$. Source: Own calculation

Table D.3: Correction method 2: Clearing the break in the unemployment series, 92-15

\begin{tabular}{lcccc}
\hline \hline & \multicolumn{4}{c}{ Dependent variable: } \\
\cline { 2 - 5 } & $(1)$ & $(2)$ & $(3)$ & $(4)$ \\
\hline Hartz IV-Dummy & $0.12^{* * *}$ & $0.09^{* * *}$ & $0.12^{* * *}$ & $0.10^{* * *}$ \\
& $(0.04)$ & $(0.03)$ & $(0.04)$ & $(0.03)$ \\
& & & & \\
log(market tightness) & $0.15^{* * *}$ & $0.27^{* * *}$ & $0.15^{* * *}$ & $0.27^{* * *}$ \\
& $(0.05)$ & $(0.04)$ & $(0.05)$ & $(0.04)$ \\
Constant & & & & \\
& $-0.56^{* * *}$ & $-2.61^{* * *}$ & $-0.56^{* * *}$ & $-2.61^{* * *}$ \\
& $(0.07)$ & $(0.06)$ & $(0.07)$ & $(0.06)$ \\
\hline Observations & & & & \\
$\mathrm{R}^{2}$ & 24 & 24 & 24 & 24 \\
Adjusted $\mathrm{R}^{2}$ & 0.54 & 0.78 & 0.54 & 0.79 \\
Residual Std. Error (df $=21)$ & 0.50 & 0.76 & 0.50 & 0.77 \\
F Statistic (df = 2; 21) & 0.09 & 0.07 & 0.09 & 0.07 \\
\hline \hline
\end{tabular}

Note: Aggregate estimation by OLS with Newey-West standard errors; ${ }^{*} p<0.1 ;{ }^{* *} p<0.05$;

${ }^{* * *} \mathrm{p}<0.01$. Source: Own calculation

\section{E Appendix: Further Evidence}

In addition, a closer look at the change of the selection rate by skill group from 2004 to $2005^{55}$ reveals that the increase in the selection rate was highest for workers with a vocationa! degree. This is exactly what we would expect: While medium-skilled workers suffered on average a larger drop in the replacement rate due to higher wages compared to low-skilled workers, they also faced a higher risk of unemployment compared to high-skill workers. ${ }^{56}$

55 Unfortunately, the IAB Job Vacancy Survey provides information on the last realised hire by skill group only from 2004 onward.

56 Unskilled workers may even have benefited from the Hartz IV reform because the standard rate for social assistance ("Sozialhilfe") was even lower than the standard rate for "Hartz IV". On the other hand, highskilled workers with a college degree face only a very small probability to fall into the pool of long-term unemployed in the first place. 


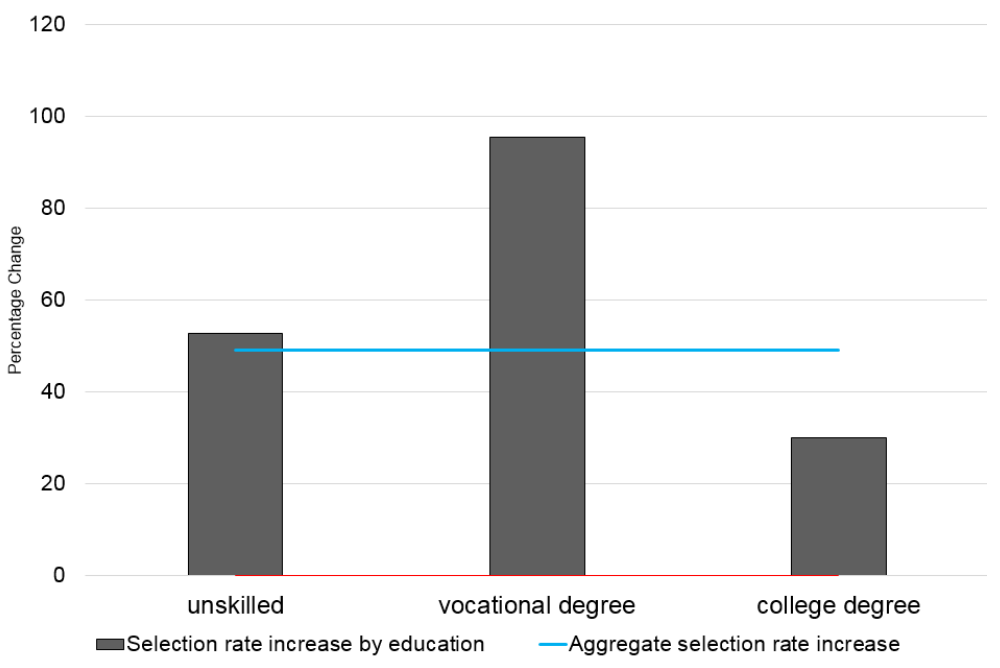

Figure E.4: Increase of selection rate by skill group, 2004-2005. Source: Own calculation based on the IAB Job Vacancy Survey

Figure E.5 shows evidence from a special survey on Hartz IV of the IAB Job Vacancy survey in which establishments were asked about their perception on changes in applicants' reservation wages and their willingness to accept special working conditions due to the Hartz IV reform. The results indicate that on average, establishments perceived that reservation wages of unemployed applicants had dropped and that their willingness to accept special working conditions had increased.

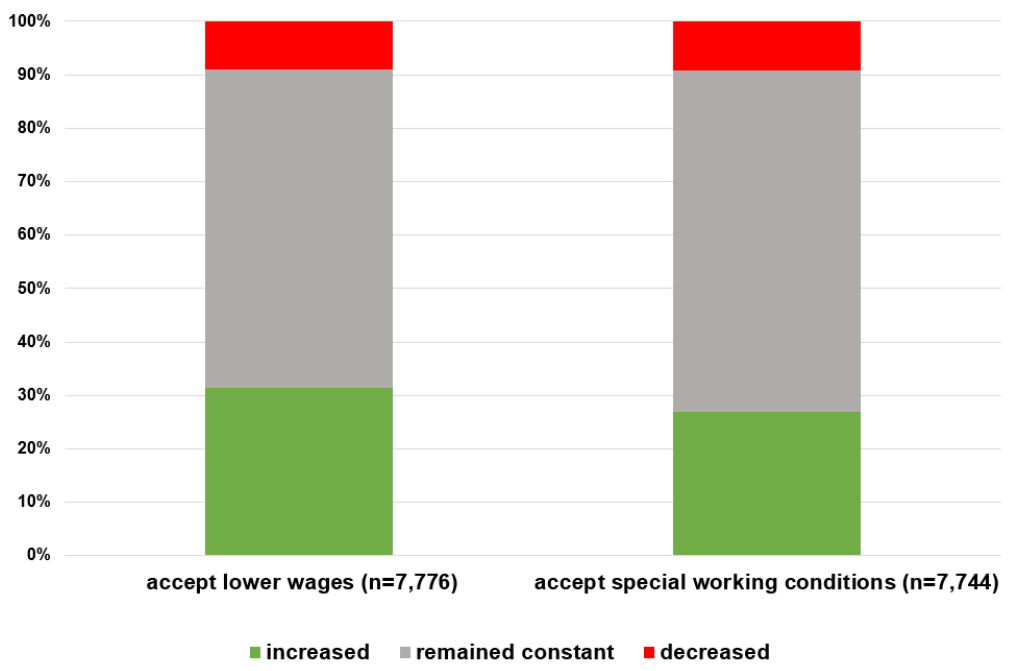

Source: Own calculation based on the IAB Job Vacancy Survey (Special survey on Hartz IV 2005/2006).

Figure E.5: The willingness of unemployed applicants to ... ( percent of establishments who gave the respective answer.) 


\section{References}

Barron, John M.; Bishop, John; Dunkelberg, William C. (1985): Employer Search: The Interviewing and Hiring of New Employees. In: The Review of Economics and Statistics, Vol. 67, No. 1, p. 43-52.

Bauer, Anja; King, Ian (2018): The Hartz Reforms, the German Miracle, and Labor Reallocation. In: European Economic Review, Vol. 103, No. C, p. 1-17.

Baydur, Ismail (2017): Worker Selection, Hiring, and Vacancies. In: American Economic Journal: Macroeconomics, Vol. 9, No. 1, p. 88-127.

Bradley, Jake; Kuegler, Alice (2019): Labor Market Reforms: An Evaluation of the Hartz Policies in Germany. In: European Economic Review, Vol. 113, p. 108 - 135.

Burda, Michael; Hunt, Jennifer (2011): What Explains the German Labor Market Miracle in the Great Recession? In: Brookings Papers on Economic Activity, Vol. 42, No. 1, p. 273-335.

Burda, Michael C.; Seele, Stefanie (2016): No Role for the Hartz Reforms? Demand and Supply Factors in the German Labor Market, 1993-2014. SFB 649 Discussion Papers 2016-010, Sonderforschungsbereich 649, Humboldt University, Berlin, Germany.

Cahuc, Pierre; Le Barbanchon, Thomas (2010): Labor Market Policy Evaluation in Equilibrium: Some Lessons of the Job Search and Matching Model. In: Labour Economics, Vol. 17, No. 1, p. 196-205.

Card, David; Johnston, Andrew; Leung, Pauline; Mas, Alexandre; Pei, Zhuan (2015a): The Effect of Unemployment Benefits on the Duration of Unemployment Insurance Receipt: New Evidence from a Regression Kink Design in Missouri, 2003-2013. In: American Economic Review, Vol. 105, No. 5, p. 126-130.

Card, David; Lee, David S.; Pei, Zhuan; Weber, Andrea (2015b): Inference on Causal Effects in a Generalized Regression Kink Design. In: Econometrica, Vol. 83, No. 6, p. 2453-2483.

Carrillo-Tudela, Carlos; Launov, Andrey; Robin, Jean-Marc (2018): The Fall in German Unemployent: A Flow Analysis. CEPR Discussion Paper DP12846.

Chugh, Sanjay; Merkl, Christian (2016): Efficiency and Labor-Market Dynamics in a Model of Labor Selection. In: International Economic Review, Vol. 57, p. 1371-1404.

Davis, Steven R.; Faberman, Jason; Haltiwanger, John C. (2013): The EstablishmentLevel Behavior of Vacancies and Hiring. In: The Quarterly Journal of Economics, Vol. 128, No. 2, p. 581-622.

Faberman, R. Jason; Mueller, Andreas I.; Şahin, Ayşegül; Topa, Giorgio (2017): Job Search Behavior among the Employed and Non-Employed. Working Paper 23731, National Bureau of Economic Research. 
Fuchs, Michaela; Jost, Oskar; Kaufmann, Klara; Ludewig, Oliver; Weyh, Antje (2018): Baustelle Arbeitsmarkt - Die Beschäftigungsdynamik in Ost und West hat sich angeglichen. https://www.iab-forum.de/baustelle-arbeitsmarkt-diebeschaeftigungsdynamik-in-ost-und-west-hat-sich-angeglichenIAB-Forum 9. November 2018, (Last accessed: January 21, 2019).

Gavazza, Alessandro; Mongey, Simon; Violante, Giovanni L. (2018): Aggregate Recruiting Intensity. In: American Economic Review, Vol. 108, No. 8, p. 2088-2127.

Hagedorn, Marcus; Karahan, Fatih; Manovskii, lourii; Mitman, Kurt (2013): Unemployment Benefits and Unemployment in the Great Recession: The Role of Macro Effects. NBER Working Papers 19499, National Bureau of Economic Research, updated version 2016.

Hartung, Benjamin; Jung, Philip; Kuhn, Moritz (2018): What Hides Behind the German Labor Market Miracle? Unemployment Insurance Reforms and Labor Market Dynamics. IZA Discussion Paper 12001, IZA Institute of Labor Economics.

Hertweck, Matthias; Sigrist, Oliver (2013): The Aggregate Effects of the Hartz Reforms in Germany. SOEPpapers on Multidisciplinary Panel Data Research 532, DIW Berlin, The German Socio-Economic Panel (SOEP).

Hirsch, Boris; Merkl, Christian; Müller, Steffen; Schnabel, Claus (2014): Centralized vs. Decentralized Wage Formation: The Role of Firms' Production Technology. IZA Discussion Paper 8242, Institute of Labor Economics (IZA).

Jacobi, Lena; Kluve, Jochen (2006): Before and After the Hartz Reforms: The Performance of Active Labour Market Policy in Germany. Tech. Rep., IZA Discussion Paper No. 2100.

Klinger, Sabine; Rothe, Thomas (2012): The Impact of Labour Market Reforms and Economic Performance on the Matching of the Short-term and the Long-term Unemployed. In: Scottish Journal of Political Economy, Vol. 59, No. 1, p. 90-114.

Kohlbrecher, Britta; Merkl, Christian; Nordmeier, Daniela (2016): Revisiting the Matching Function. In: Journal of Economic Dynamics and Control, Vol. 69, p. 350-374.

Krause, Michael; Lubik, Thomas (2007): The (Ir)Relevance of Real Wage Rigidity in the New Keynesian Model with Search Frictions. In: Journal of Monetary Economics, Vol. 54, No. 3, p. 706-727.

Krause, Michael; Uhlig, Harald (2012): Transitions in the German Labor Market: Structure and Crisis. In: Journal of Monetary Economics, Vol. 59, No. 1, p. 64-79.

Krebs, Tom; Scheffel, Martin (2013): Macroeconomic Evaluation of Labor Market Reform in Germany. In: IMF Economic Review, Vol. 61, No. 4, p. 664-701.

Krueger, Alan B.; Meyer, Bruce D. (2002): Labor Supply Effects of Social Insurance. Vol. 4 of Handbook of Public Economics, chap. 33, Elsevier, 1 ed., p. 2327-2392.

Launov, Andrey; Wälde, Klaus (2016): The Employment Effect of Reforming a Public Employment Agency. In: European Economic Review, Vol. 84, No. C, p. 140-164. 
Launov, Andrey; Wälde, Klaus (2013): Estimating Incentive and Welfare Effects of Nonstationary Unemployment Benefits. In: International Economic Review, Vol. 54, p. 1159-1198.

Lechthaler, Wolfgang; Merkl, Christian; Snower, Dennis J. (2010): Monetary Persistence and the Labor Market: A New Perspective. In: Journal of Economic Dynamics and Control, Vol. 34, No. 5, p. 968-983.

Moczall, Andreas; Anne, Müller; Rebien, Martina; Vogler-Ludwig, Kurt (2015): The IAB Job Vacancy Survey. Establishment Survey On Job Vacancies and Recruitment Processes. Waves 2000 to 2013 and Subsequent Quarters from 2006. FDZ Datenreport 201504, Research Data Centre (FDZ) of the German Federal Employment Agency (BA) at the Institute for Employment Research (IAB).

Pissarides, Christopher A. (2000): Equilibrium Unemployment Theory, 2nd Edition, Vol. 1 of MIT Press Books. The MIT Press.

Price, Brendan (2018): The Duration and Wage Effects of Long-Term Unemployment Benefits: Evidence from Germany's Hartz IV Reform, university of California, Davis, mimeo.

Rothe, Thomas; Wälde, Klaus (2017): Where Did All the Unemployed Go? Non-standard Work in Germany after the Hartz Reforms. Discussion Paper 1709, Gutenberg School of Management and Economics \& Research Unit Interdisciplinary Public Policy.

Schmieder, Johannes F.; von Wachter, Till; Bender, Stefan (2016): The Effect of Unemployment Benefits and Nonemployment Durations on Wages. In: American Economic Review, Vol. 106, No. 3, p. 739-77.

Sedlaĉek, Petr (2014): Match Efficiency and Firms' Hiring Standards. In: Journal of Monetary Economics, Vol. 62, No. C, p. 123-133.

Seeleib-Kaiser, Martin (2016): The End of the Conservative German Welfare State Model. In: Social Policy and Administration, Vol. 50, No. 2, p. 219-240.

Statistik der Bundesagentur für Arbeit (2005): Der Übergang von der Arbeitslosen- und Sozialhilfe zur Grundsicherung für Arbeitsuchende. Sonderbericht, Bundesagentur für Arbeit, Nürnberg.

Trappmann, Mark; Beste, Jonas; Bethmann, Arne; Müller, Gerrit (2013): The PASS Panel Survey after Six Waves. In: Journal for Labour Market Research, Vol. 46, No. 4, p. 275281.

vom Berge, Philipp; Burghardt, Anja; Trenkle, Simon (2013): Sample of Integrated Labour Market Biographies - Regional file 1975-2010 (SIAB-R 7510). FDZ-Datenreport, 09/2013, Nuremberg. 


\section{Imprint}

\section{IAB-Discussion Paper IAB 3|2019}

Publication date

21 February 2019

Editorial address

Institute for Employment Research

of the Federal Employment Agency

Regensburger Straße 104

90478 Nürnberg

Germany

All rights reserved

Reproduction and distribution in any form, also in parts, requires the permission of IAB Nuremberg

Download of this Discussion Paper

http://doku.iab.de/discussionpapers/2019/dp0319.pdf

All publications in the series "IAB-Discussion Paper" can be downloaded from

https://www.iab.de/en/publikationen/discussionpaper.aspx

Website

www.iab.de

ISSN

2195-2663

For further inquiries contact the author

Hermann Gartner

Telefon 0911 179-3386

E-Mail Hermann.Gartner@iab.de 